من المؤكد إن الديمقراطية ليست مجرد مؤسسات وإجراءات فحسب، لكنها إلى

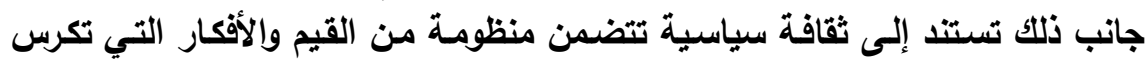

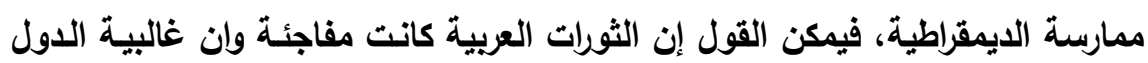

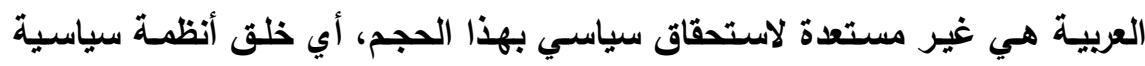

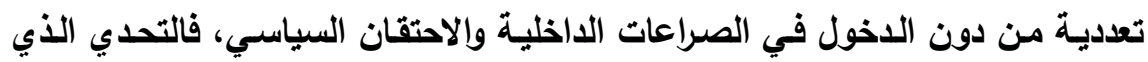

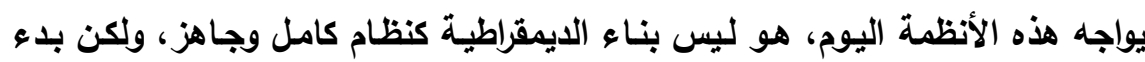

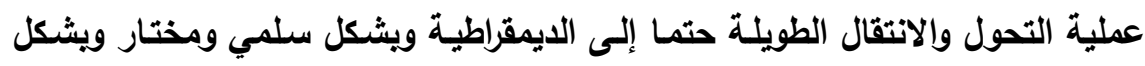
واع منظم بما يجنبها الصراعات الاموية والانفجارات والحروب الداخلية والخارئية ولثارية.

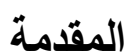

مقارت الديمقراطية - في العصر الحديث- انتصاراً تاريخيا (Victory)

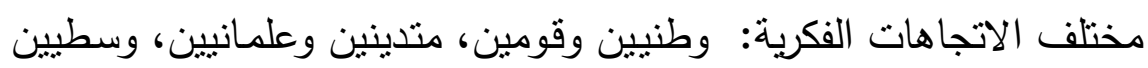

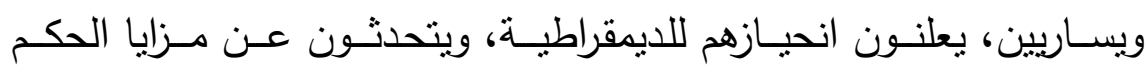

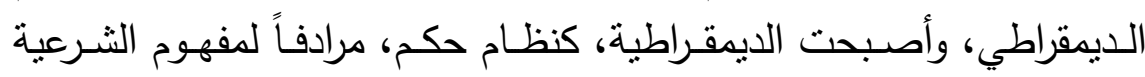
(Legitimacy)

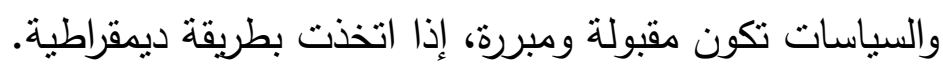

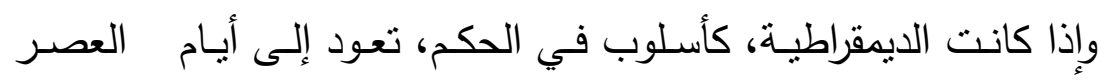
اليوناني القديم في القرن الخامس قبل الميلاد، فإن نظام الحكم الديمقراطي الـي 


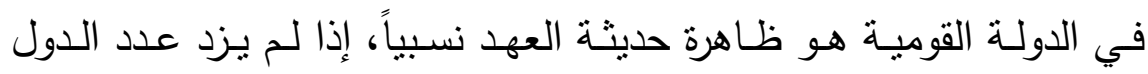

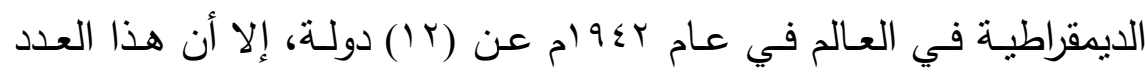

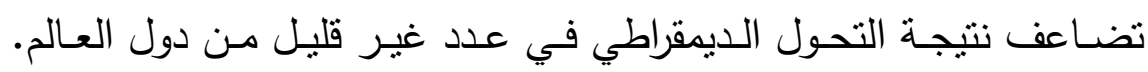

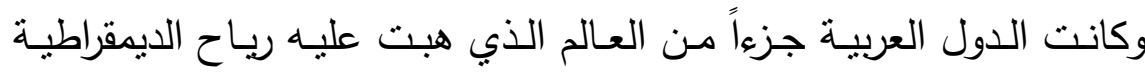

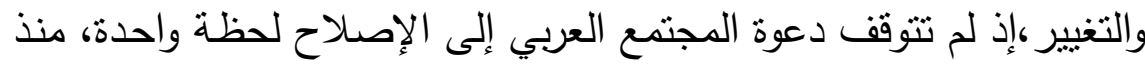
استقلال البلدان العربية.

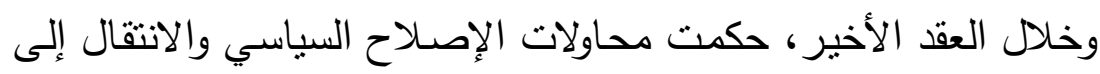

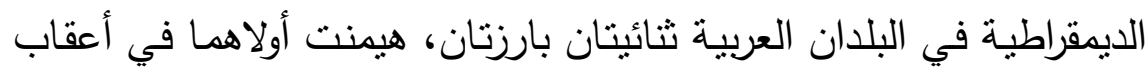

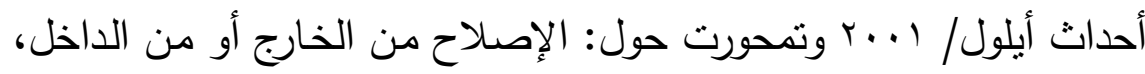

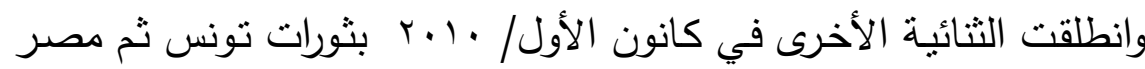

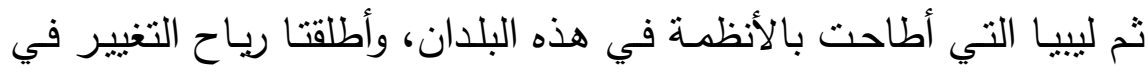

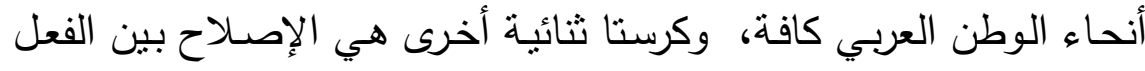
الثوري والإصلاح التدريجي.

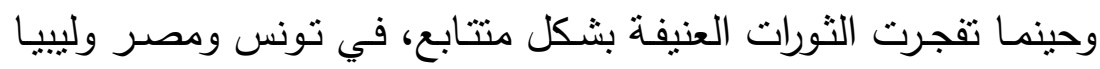

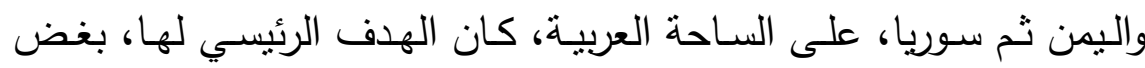

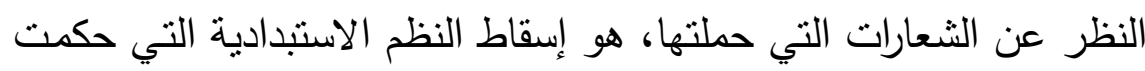

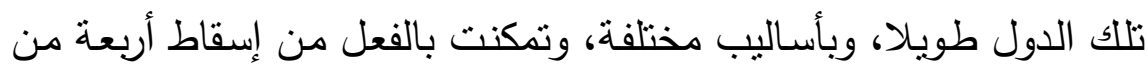

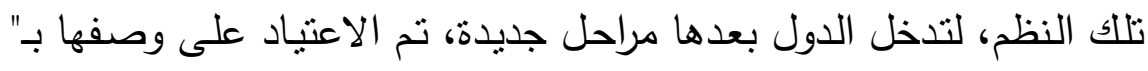

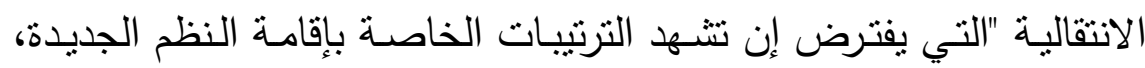

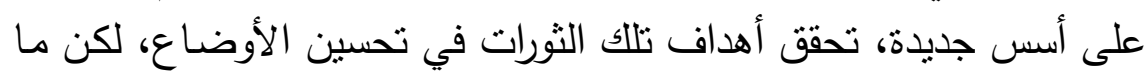

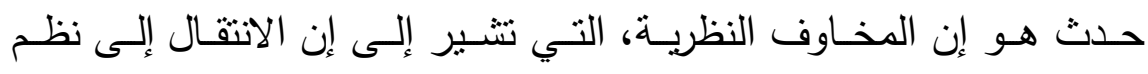

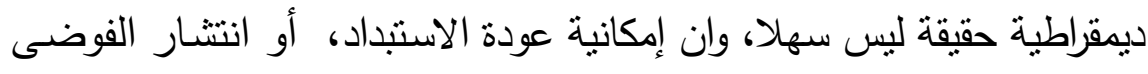

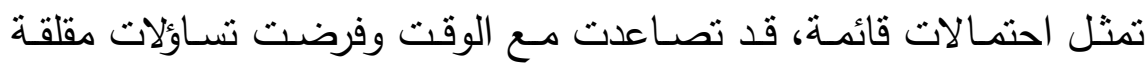

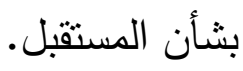


هنـاك فـرق مـابين التحـول الـديمقراطي وترسـيخ الـديمقراطي... فحدوث التحول الديمقراطي أمر واستمرار وتعزيز الديمقراطية أمر أخر تماما، فإن

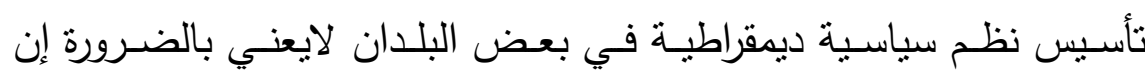

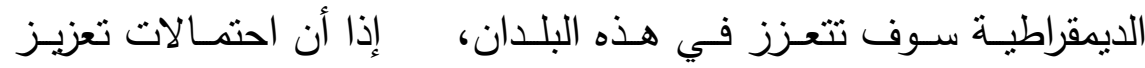

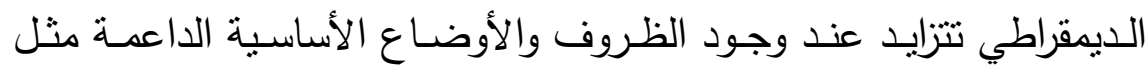
التغيير التدريجي المعتدل، وكذلك عندما يوجد عدد كاف مـن الفـاعلين

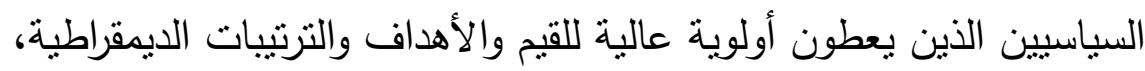

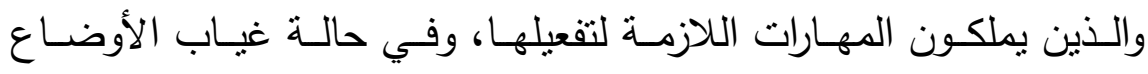
والظروف تتضاءل احتمالات ترسيخ الديمقراطية، ومما يؤدي إلى حالة عدم الاستقرار السياسي في تللك الدول.

\section{فرضية البحث: ينطلق البحث من فرضيتين}

أولا- هناك علاقة طردية بين عدم الاستقرار السياسي والمطالب السياسية.

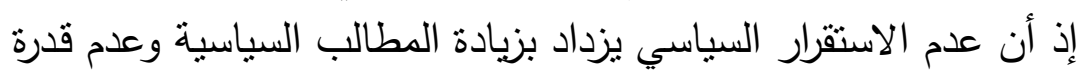

المؤسسات السياسية على الاستجابة لها.

ثانيا- الفرضية الأخرى هي أن التغيير الاجتماعي لا يكون ثوريا، إلا إذا

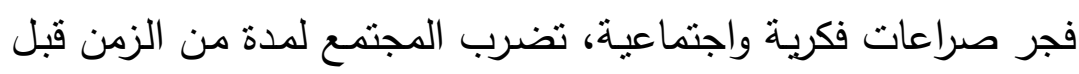
أن يحقق استقراره. كما ارتكز البحث على المينىراره المعادلتين التاليتين:

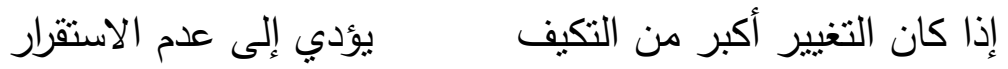

$$
\begin{aligned}
& \text { إذا كان التغيير أصغر من التكيف يؤدي إلى الاستقرار }
\end{aligned}
$$

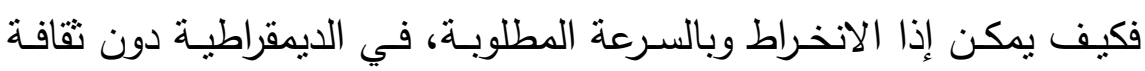
ومؤهلات ديمقراطية؟ ومن خلال هذه الفرضيات والمعادلات تم تقسيم البحث إلى المحاور الآتية: 
أولا: تأصيل نظري لبعض المفاهيم

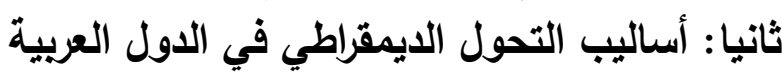

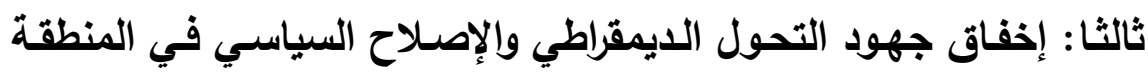

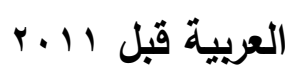

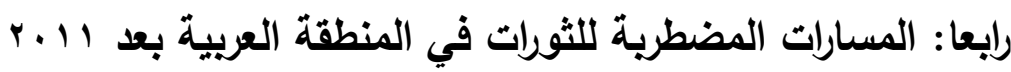
أولا: تأصيل نظري لبعض المفاهيم

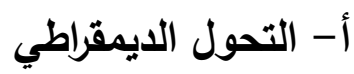

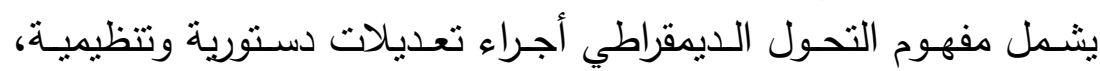

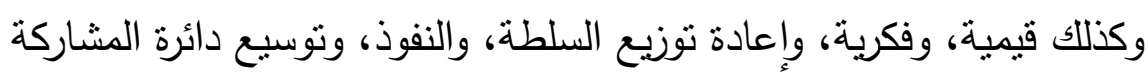

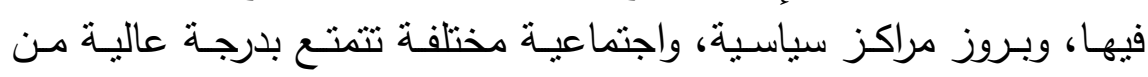
الاستقال (') وخلال هذه العملية فان الجسم السياسي والاجتماعي ينتابه قدر

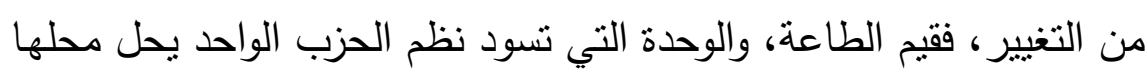

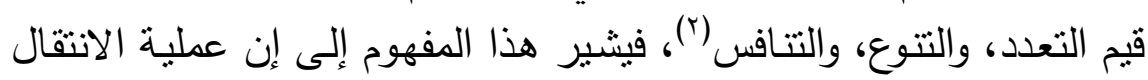

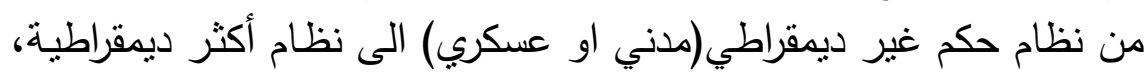

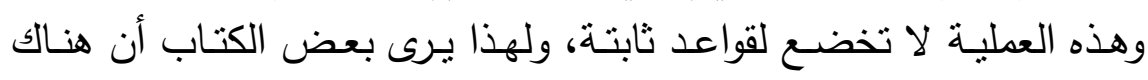

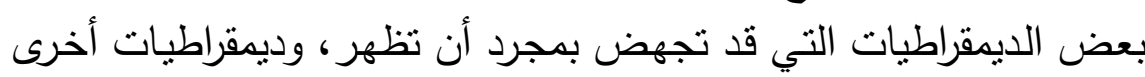

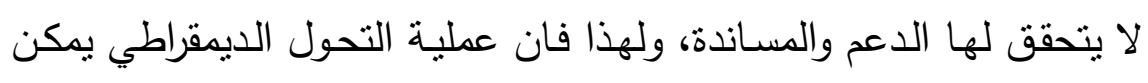

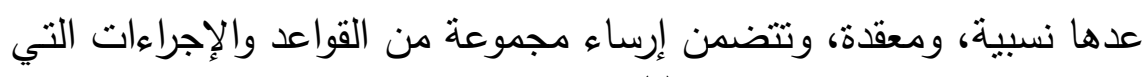

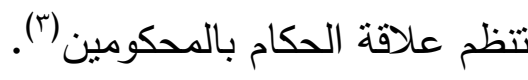
ترصد العديد من الدراسات آليات التحول الديمقراطي وتحلاتها وفيما يلي لالي عرض موجز لأهم هذه الآليات: (1) التحول من أعلى: حيث تأتي المبادرة بدفع النظام باتجاه الديمقراطية

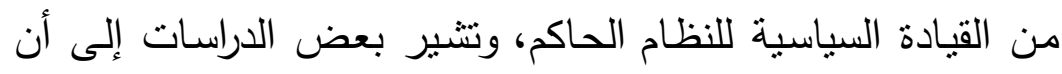

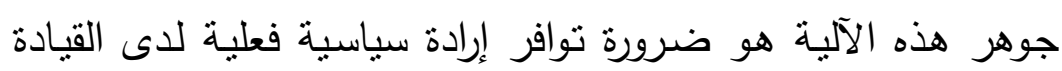




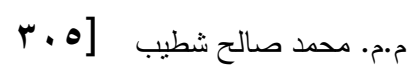

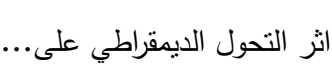

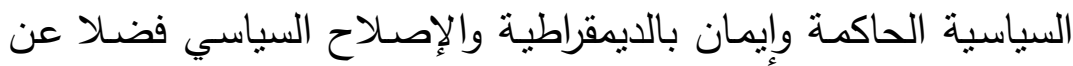
قدرتها على التغلب على المعوقات التي تقف أمام أبي تحرك باتجانهاه

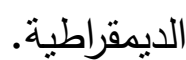

(r) التحول الديمقراطي من خلال التفاوض:ومنة ومن هذه الحالة تأتي المبادرة

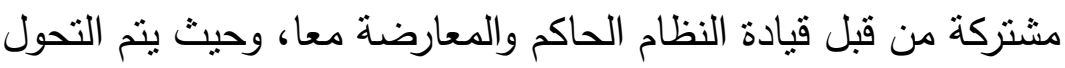

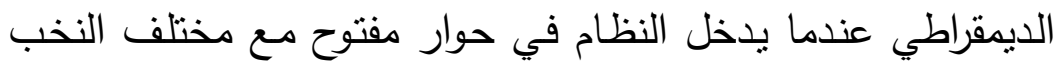

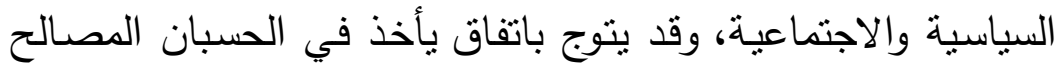
الحيوية لكافة القوى السياسية المشاركة فيه.

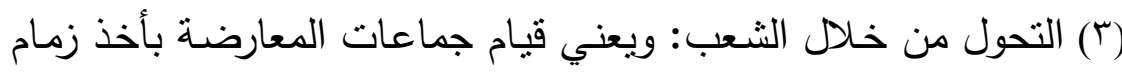

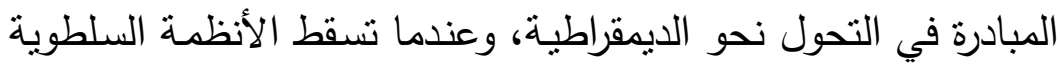
أو قد يحدث التحول نتيجة وفاة الحاكم الديكتاتور ومبادرة خلفه بعملية التحانية

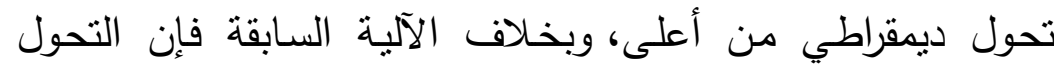

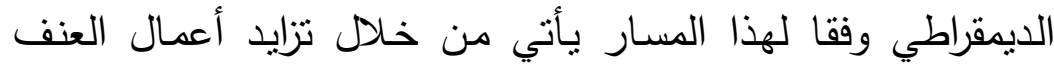

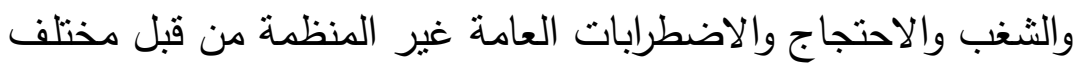

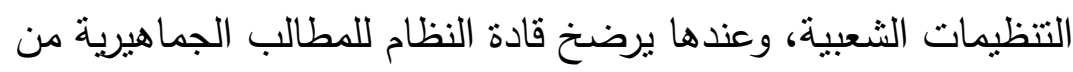
أجل احتواء الأزمة (ई).

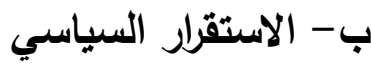

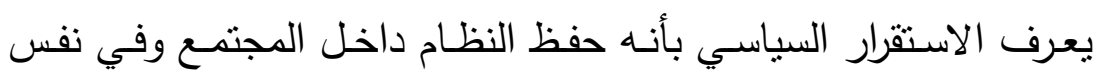

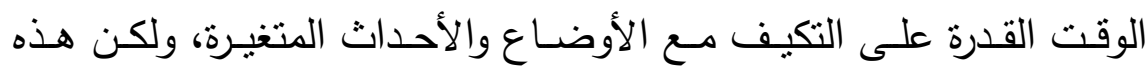

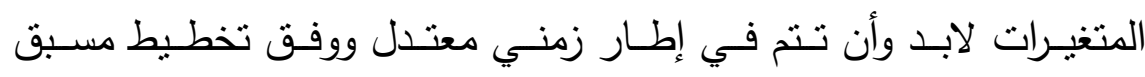
للمحافظة على نوازن النظام (0). وتثير د. نيفين مسعد (الأستاذة في جامعة القاهرة) إلى مفهوم الاستقرار

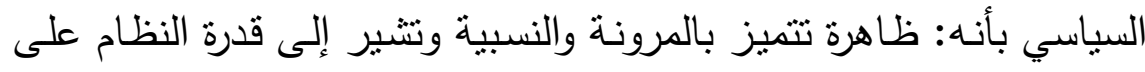

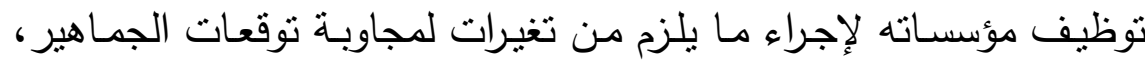


واحتواء مـا قد ينشـأ مـن صـراعات دون استخدام العنف السياسـي إلا في أضيق نطاق، دعماً لشرعيته وفعاليته(آ). في حين يتجه أصحاب المدرسة السلوكية إلى تعريف الاستقرار السياسي

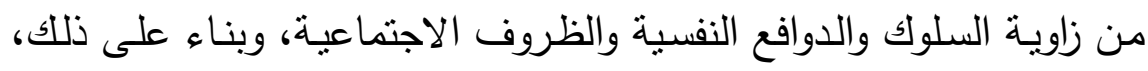

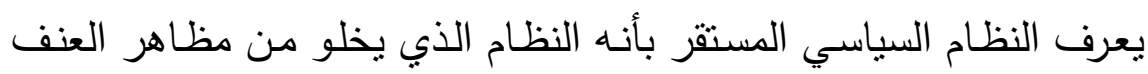

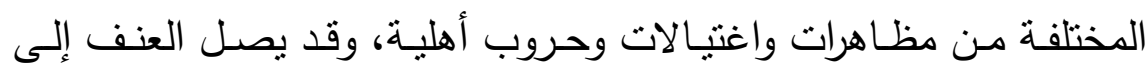
أقصى صوره وهي الثورة، بمعنى آخر هو النظام الذي تتمثل شرعية السلطة فيه في الطاعة واحترام القانون (v).

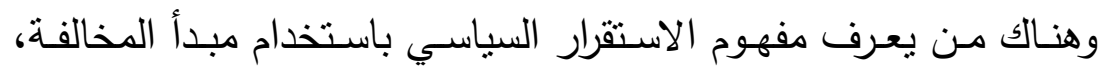

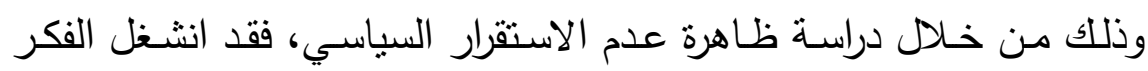
السياسي بتحليل عوامل عدم الاستقرار السياسـي مثنل التفاوت الاجتمـاعي

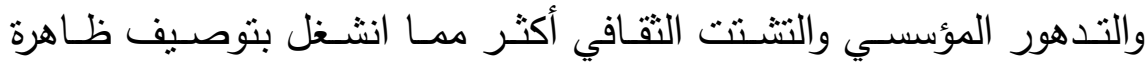
الاستقرار السياسي في حد ذاته، فهناك من يعرف مفهوم عدم الاستقرار

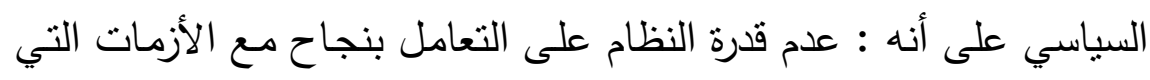

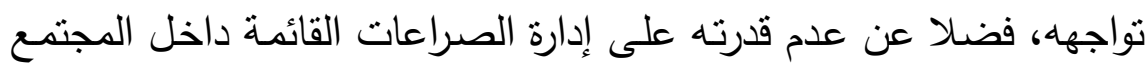

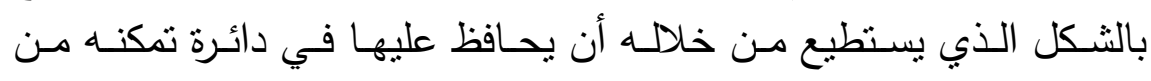

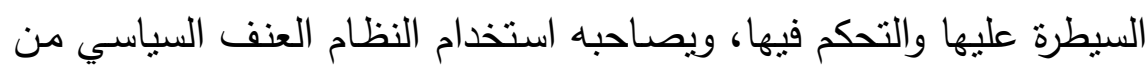
جهة، وتتاقص شرعيته وكفاءته من جهة أخرى(). مجمل هذه المفاهيم تفيد

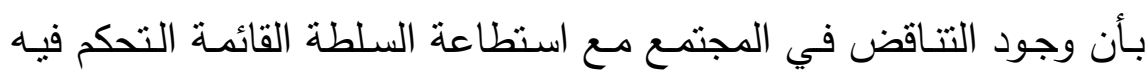
سيؤدي إلى الاستقرار السياسي، ولكن إذا ما فنست السلطة في التهاعة التحكم فيه فيقود ذلك إلى عدم استقرار السياسي وتتاقص شرعية النظام.

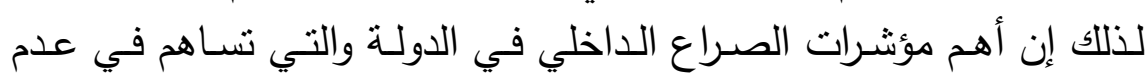

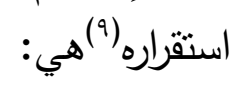

(1) عدد الاغتيالات السياسية داخل الدولة .

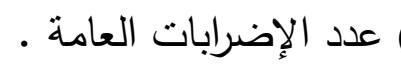


P.V] [م. محد صالح شطيب

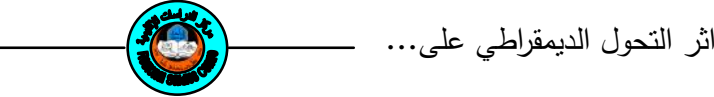

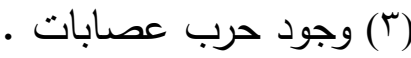

(§) عدد الأزمات الحكومية داخل البناء السياسي.

(0) عدد عمليات التطهير التي تتم في أجهزة الدولة.

(7) عدد أعمال الثغب داخل نظام الدولة.

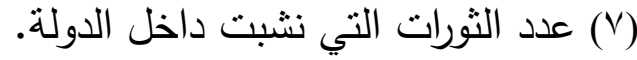

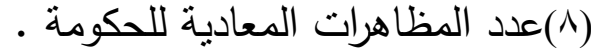

(9) عدد القتلى الذين لقوا مصرعهم في كل صور العنف المحلي.

تقود كل هذه المؤشرات إلى مرحلة تعد فيها المؤشرين الأساسيين لحالة

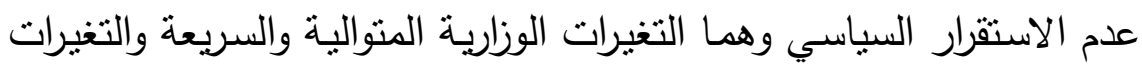

في النظام نفسه بسبب الانقلابات العسكرية.

ج- مؤثرات الاستقرار السياسي

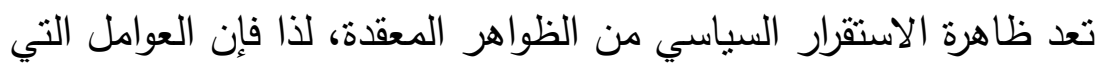

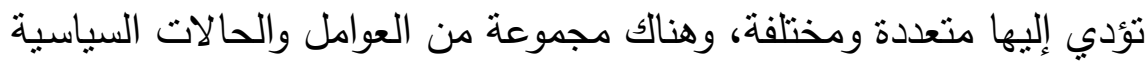

$$
\text { والتي يمكن عدها من أهم مؤشرات الاستقرار السياسي وهي: }
$$

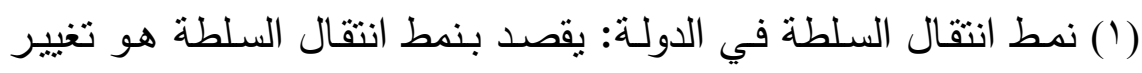

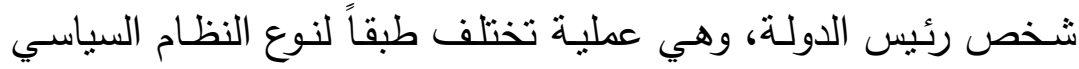

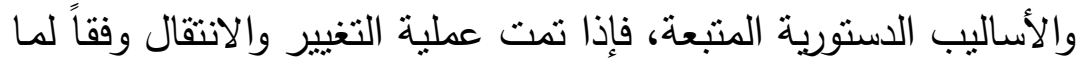

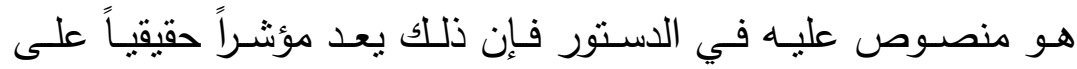

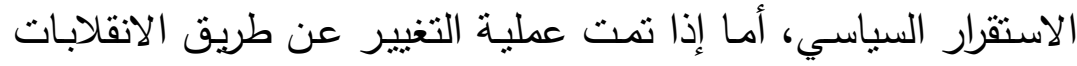

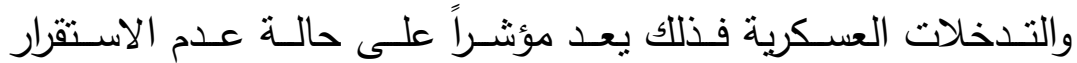

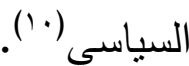

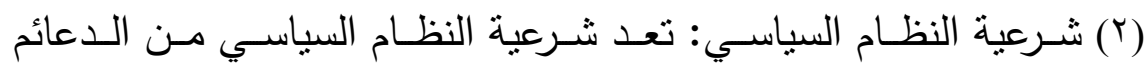

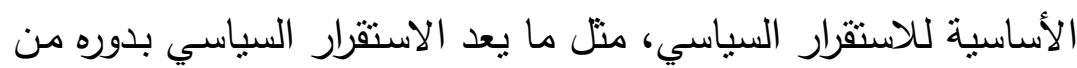

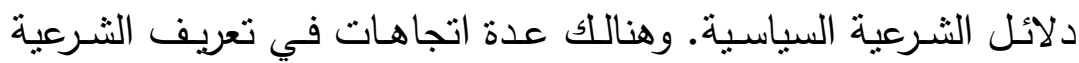


السياسية: قانوني، سياسي، ديني، والذي يهمنا هو الاتجاه السياسي،

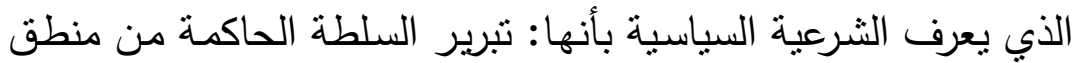

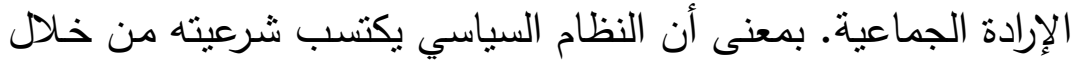
تحقيق مصالح الثُبب وصيانة استقلال البلاد وحماية الحقوق المدنية

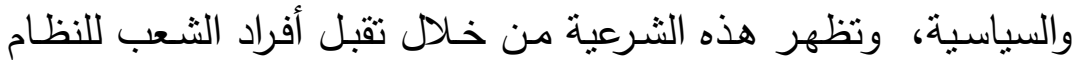
وخضوعهم لله طواعية (1')

(r) تدعيم المشاركة السياسية : تعد المشاركة السياسية أحد مقاييس ووصف

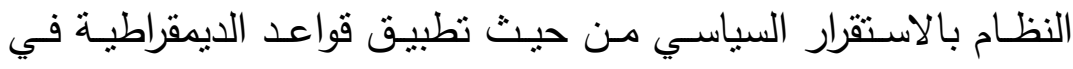

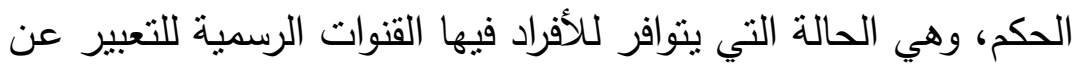

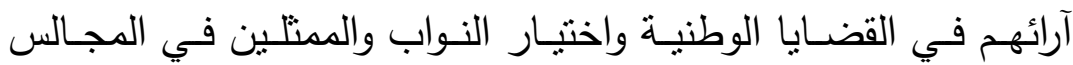

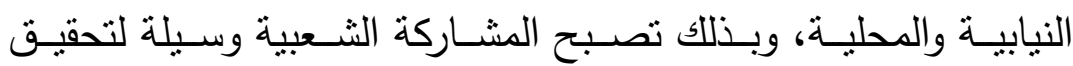
الاستقرار السياسي الداخلي وتدعيم شرعية السلطة السياسية.

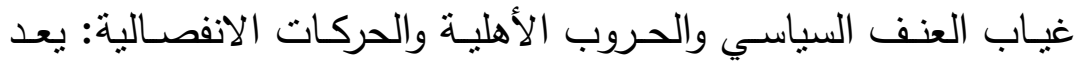
غيـاب العنف السياسـي دليـل التغييـر الـرئيس لحالـة عـدم الاسـتقرار

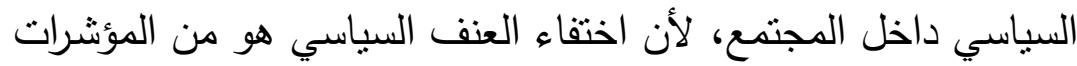

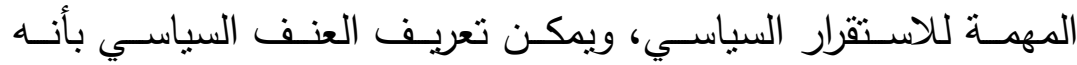
الاستخدام الفعلي للقوة المادية لإلحاق الضرر بالآخرين، وذلك لتحقيق لتهان

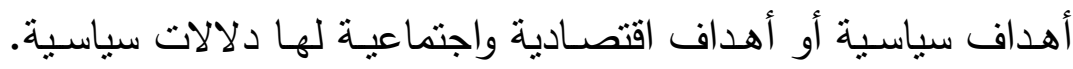
والعنف السياسي قد يكون على المستوى الرسمي أو على المستوى غير الهير

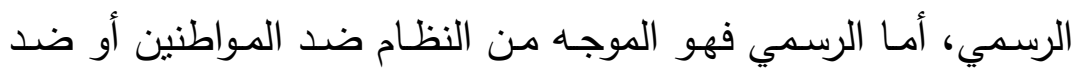

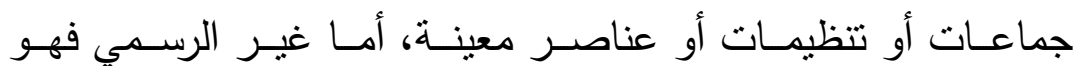
الموجهة من المواطنين أو الجماعات ضداعد النظام السياسي، وبالنسبة النية

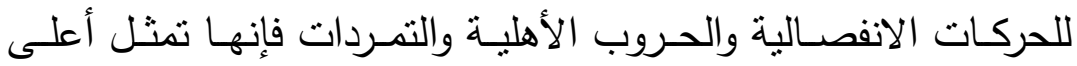

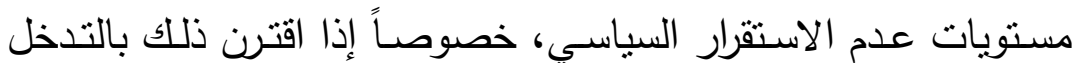

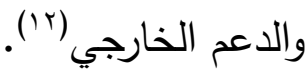


( ) الوحدة الوطنية والتكامل القومي: إن ظاهرة التعددية في المجتمعات هي

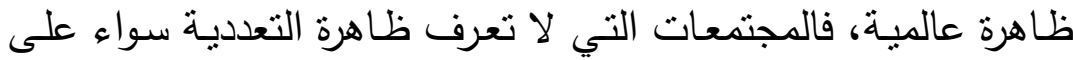

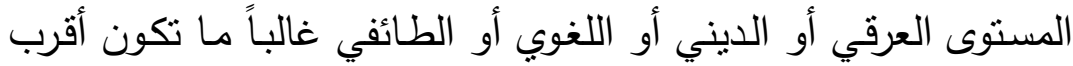

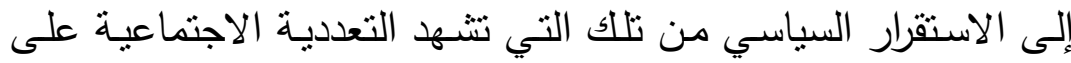

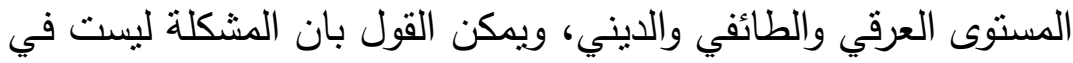
وجود هذه التعدديـة الاجنماعية وإنما في اسنتراتيجيات النخب ولئ الحاكمـة

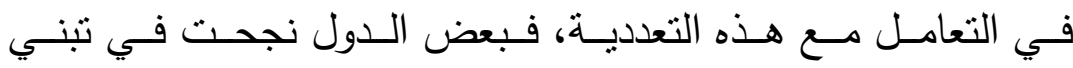
اسـتراتيجيات صـحيحة وحولت هـذه التعدديـة إلى عنى هـر ثـراء وقوة

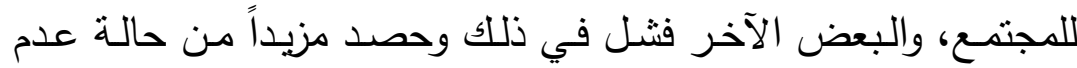

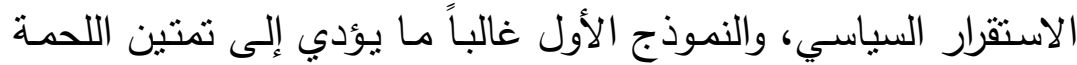

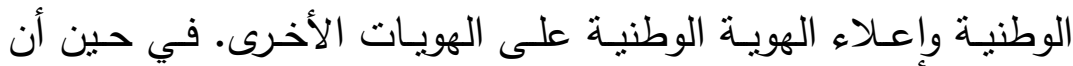

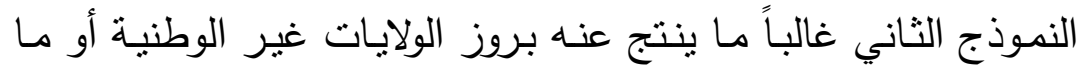

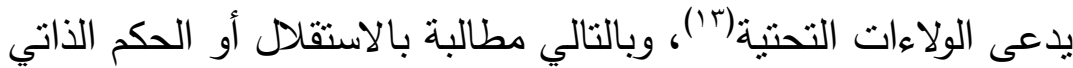
كما حدث في العراق والسودان.

(7) الفعالية السياسية: إن النظام السياسي الذي يتمكن من تغيير سياسـاته

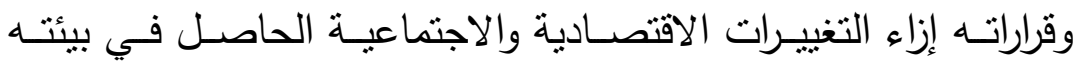
الداخليـة هو النظـام الذي يستطيع تحقيـق شرعيته ويضـمن الاستقرار

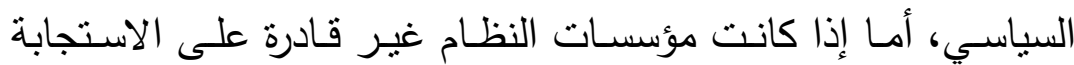
للتغيرات في البيئة الداخلية فإن ذلك سيكون مدعاة إلى عدم الاستقرار

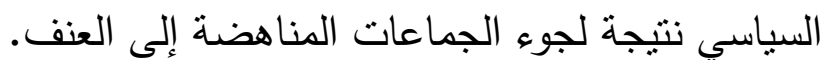

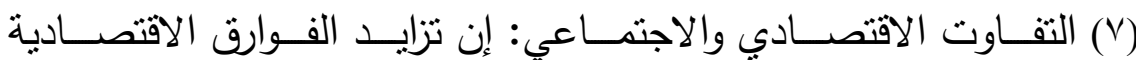
والاجتماعية بين إفراد المجتمع بؤدي إلى الحرمان النسبي، والذي بدوره

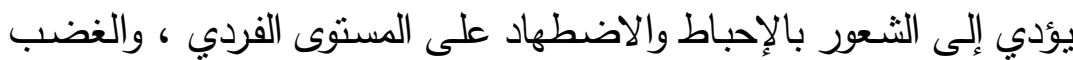
الاجتماعي والسخط العام على المستوى الجماعي، مما يدفع الجماعات

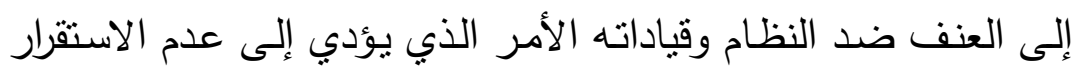


السياسي، واستمرار التفاوت الاقتصـادي والاجتماعي يؤدي إلى تفجير

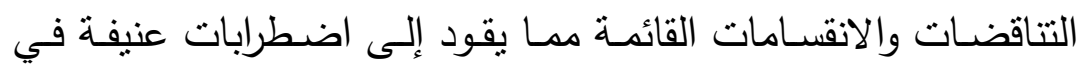
أشكال شتى: حركات انفصالية، حروب أهلية وغيرها (؛ ().

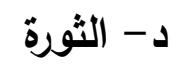

كلمة (الثورة) تجري على كل لسان وتخطها الأقلام ويتتاقش فيها الناس ويتشاغلون بها وما أكثر الأنظمة السياسية التي تدعي بأنها ثورية وما أكثر

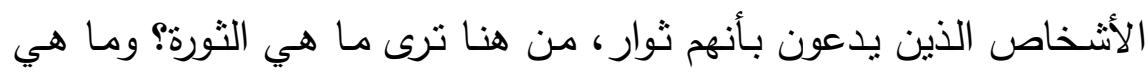
خصائصها؟ فالثورة تعني ذلك العلم الذي يهدف إلى تغيير المجتمع تغييرا

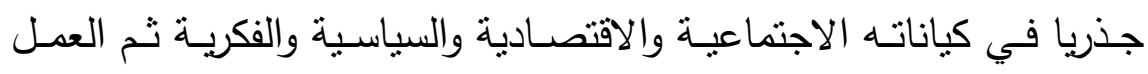

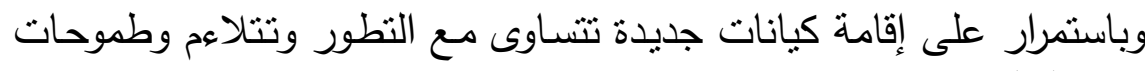

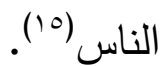

والثورة من الوجهة السياسية هي (حركة شعبية واسعة ذات توجه سياسي منظم تعبر عن الرغبة العامة لجموع أفراد الثعب وتهدف إلى تغيير النظام

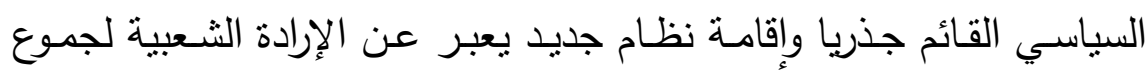

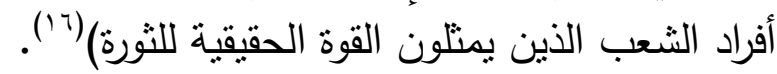

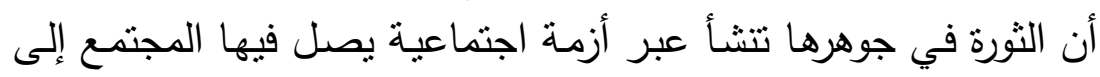

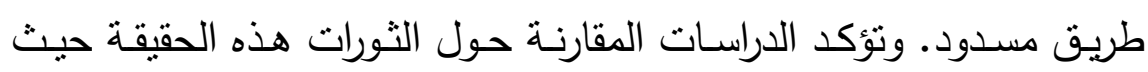

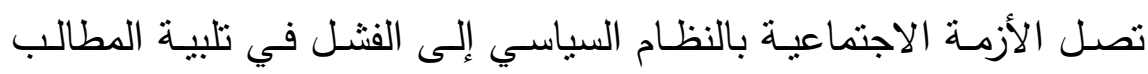

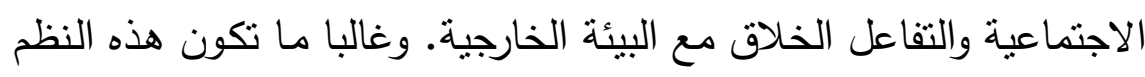

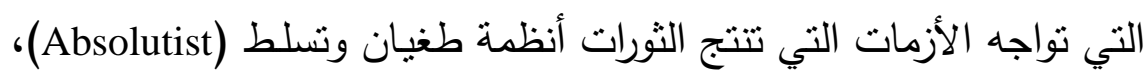
تتشخل بالمحافظة علي النظام الداخلي، ومن ثم تتحول بالتدريج إلي نظم

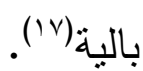
وتعد الثورة من أهم مظاهر التعبير عن الرفض الثعبي للأنظمة الحاكمة

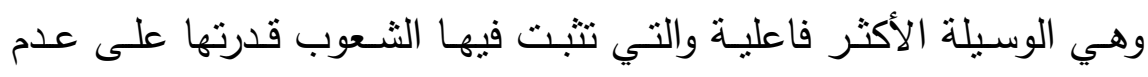




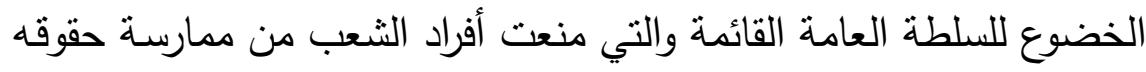

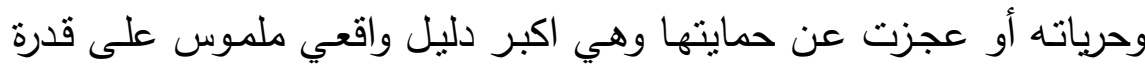
الثعب على فرض إرادته والتعبير عن سيادته الوطنية.

ثنانيا: أساليب التحول الديمقراطي في الاول العربية

أ- الإصلاح السياسي من الخارج

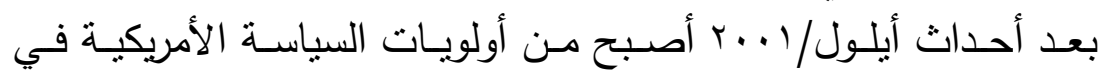

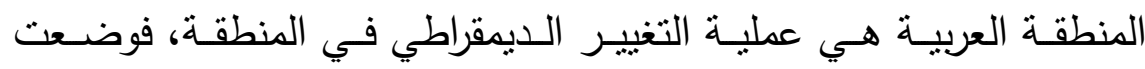

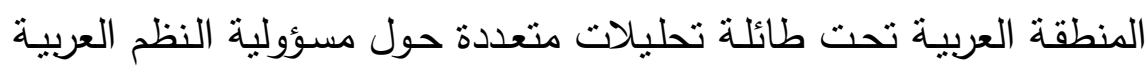

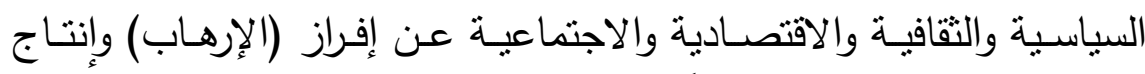

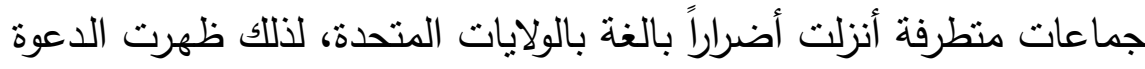

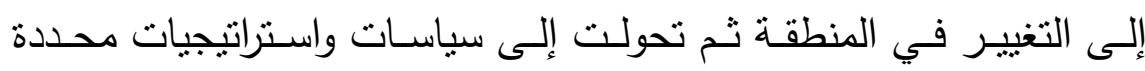
تتماشى مع مصالح الولايات المتحدة الأمريكية وحلفائها (^)".

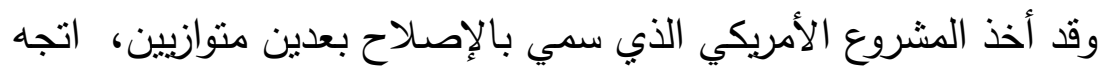

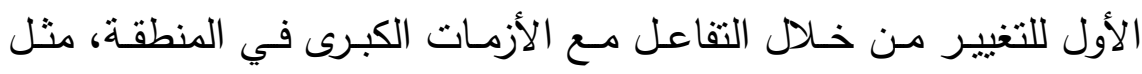
العراق وفلسطين ولبنان والسودان من دون الاكتراث بما يرتكب من النتهاكات الآنات

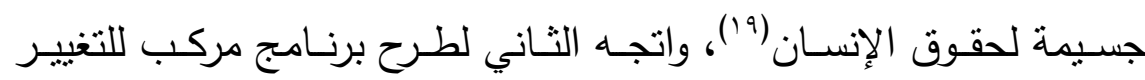

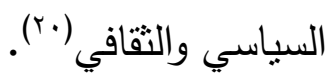

ب- الإصلاح السياسي من الداخل

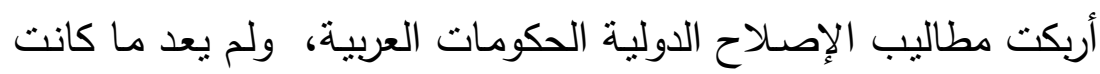

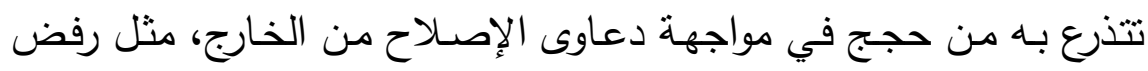

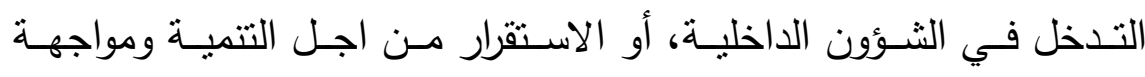

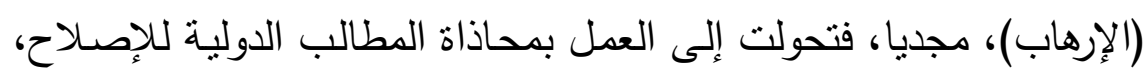


واستيعاب المطالب الداخلية، وليس التفاعل معها وإزاء هذا الوضـع وجدت هذه النظم نفسها أمام خيارين (rابل):

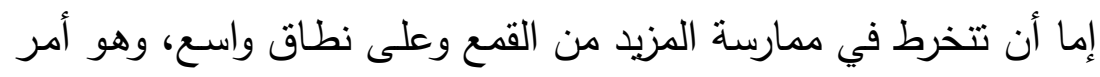

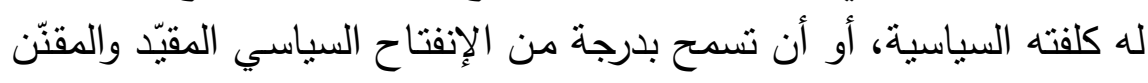

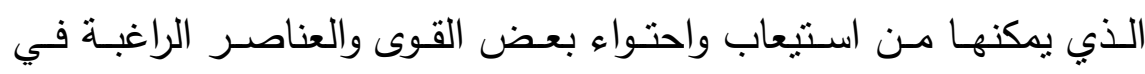

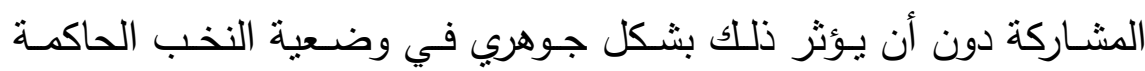
ونمط ممارسة السلطة.

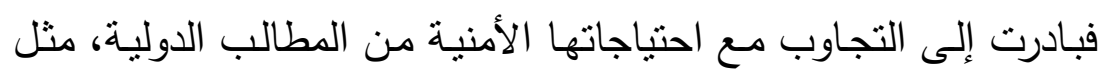

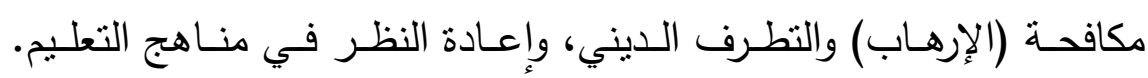

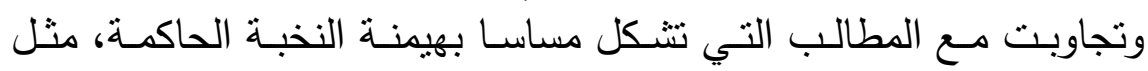

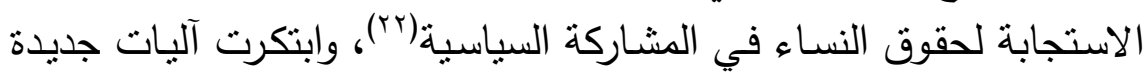

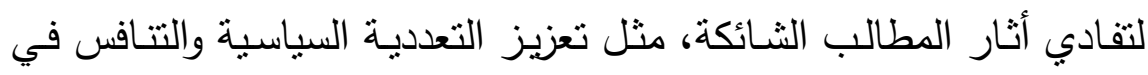
الانتخابات، فعدِل بعضاً من قوانينها الانتخابية على نحو يقبل بهذه التعددية

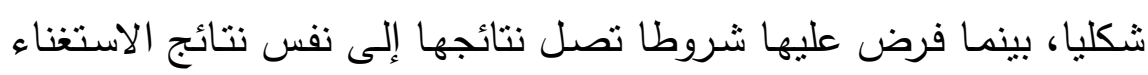

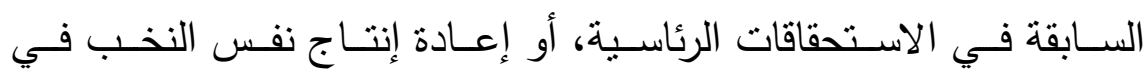
الانتخابات النيابية والبلدية الابهية التهات

\section{ج- التغييز الثوري}

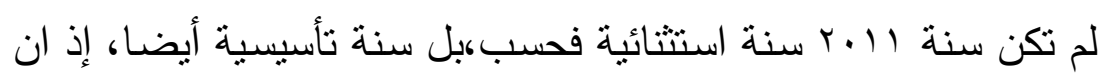
تحولات هذه السنة هي من العمق بحيث إنها تلغي ما قبلها، من مؤسسات وشخصيات وعقليات وسلوكيات، وتؤسس لكل ما بعدها، أحداث هذه السنة

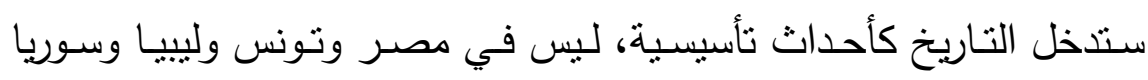

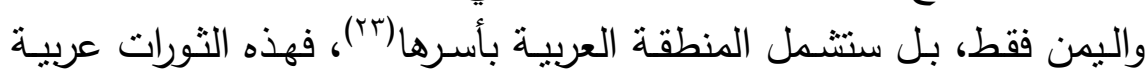
خالصة وبدون تلخخل خارجي. 
rir]

م.م. محمد صالح شطيب

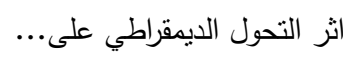

ولأول مرة تأخذ الثورة ضد النظام السياسي صفة عربية، بعد ان كانت

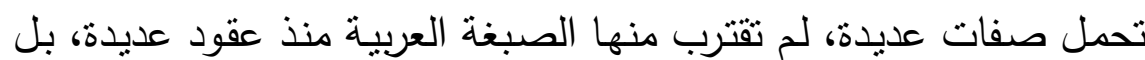
منذ قرون عديدة، حيث لم تحدث ثورة عربية، قادها شعب عربي في تاريخها الحديث، وكنا نقرأ ونسمع عن الثورات، كالثورة الفرنسية، والثورة الأميركية،

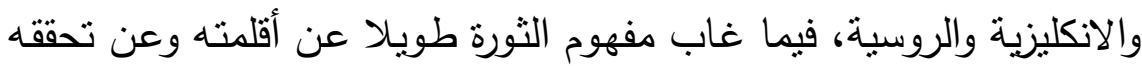

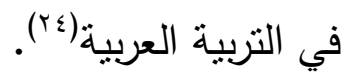

من الملاحظ أن المنطقة العربية تعيش تحولات تاريخية وتستورد نوصيفها

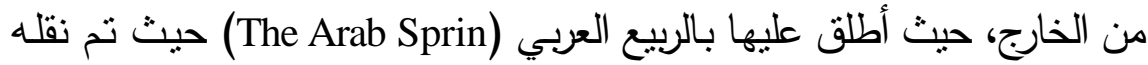
من تجارب عالمية على الرغم من شيوع استخدامه من قبل وسائل الإعلام

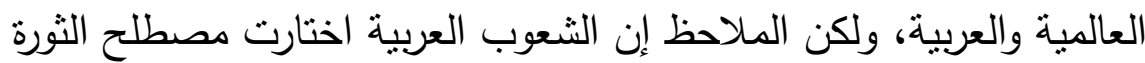
العربية (The Arab Revolution) وانحازت إلى وصف ما تقوم به بالثورة في تونس ومصر وليييا واليمن وسوريا.

ثالثا: إخفاق جهود التحول الايمقراطي و الإصلاح السياسي في المنطقة

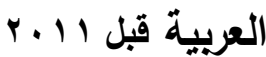

يعد التحول نحو الديمقراطية من أهم عوامل توطيد الاستقرار السياسي والاجتماعي والأمني، وذلك لان تداول السلطة عن طريق انتخابات تعددية

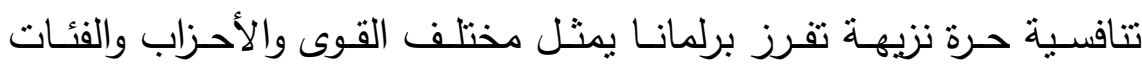

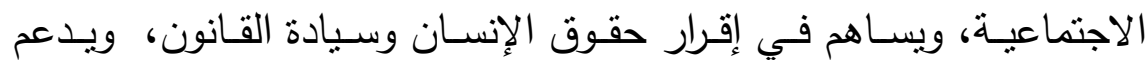

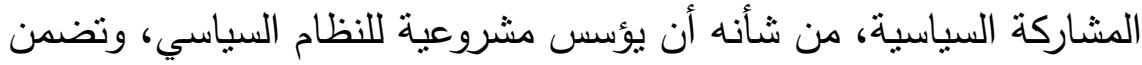

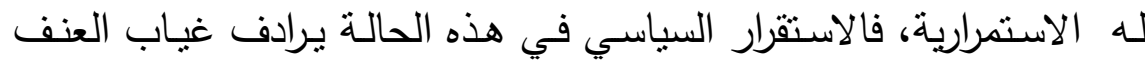

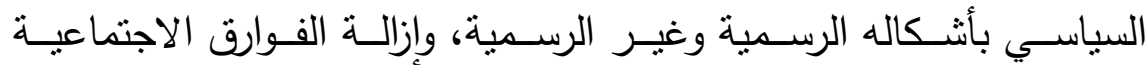
والاقتصادية بين الجماعات داخل الدولة(ro).

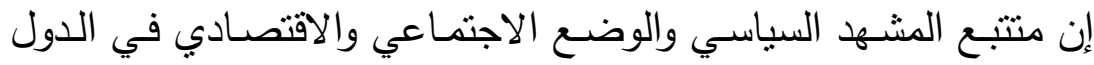
العربية يلاحظ الهوة بين الخطاب الحداثي والممارسة السياسية على مستوى الإئي 
الواقع، والفجوة بين الأطر والهياكل الدستورية والمؤسسية الرسمية من ناحية،

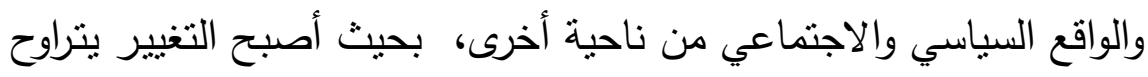

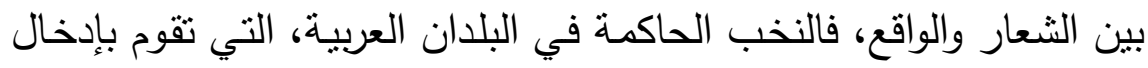

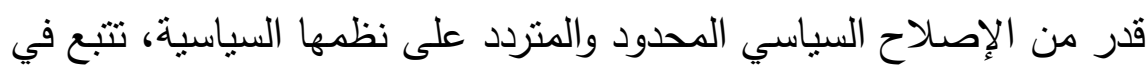

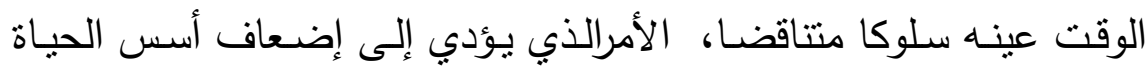

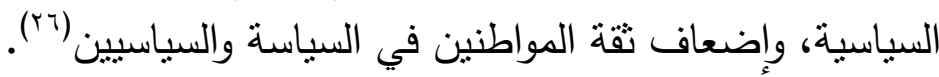

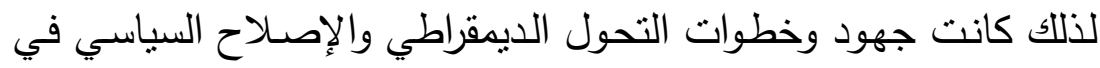

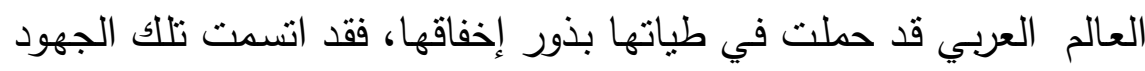

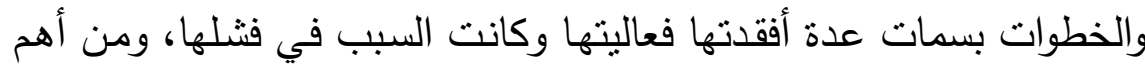

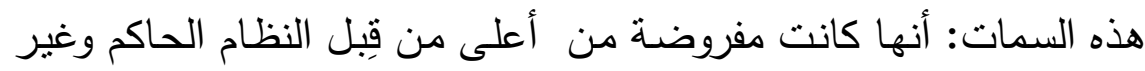

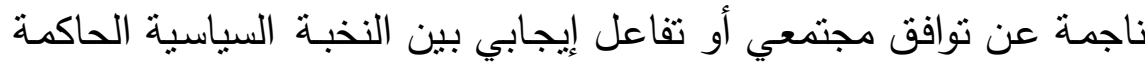

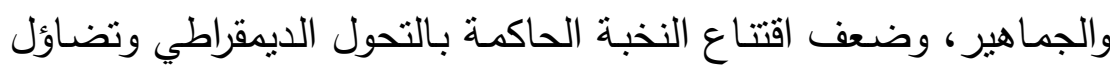

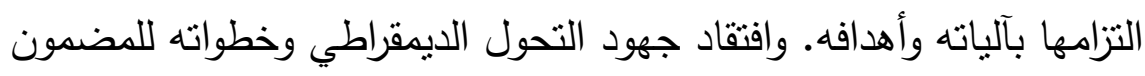

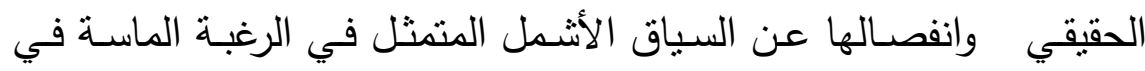

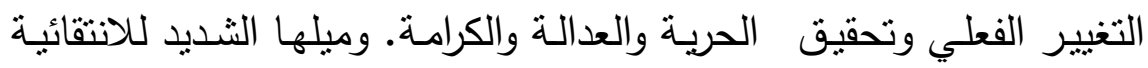

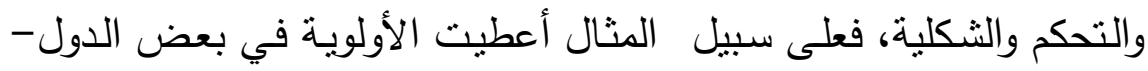

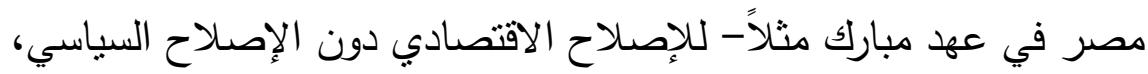

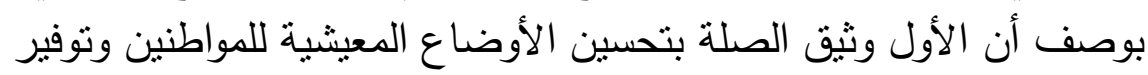

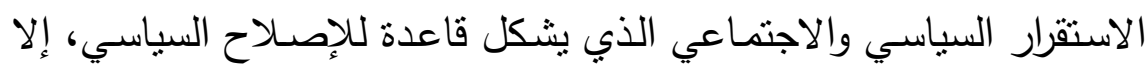

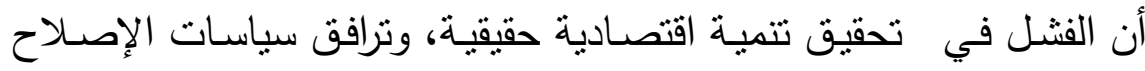

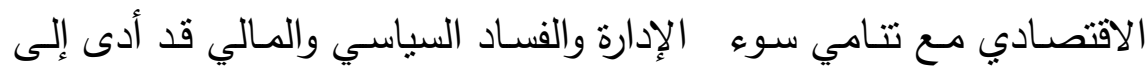

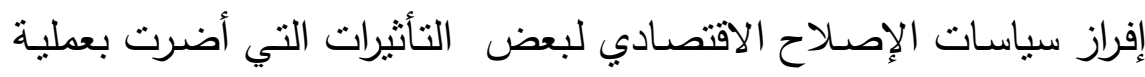

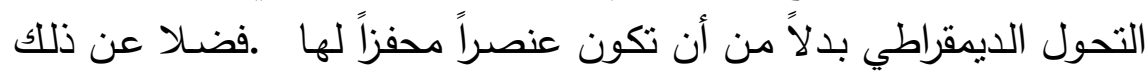

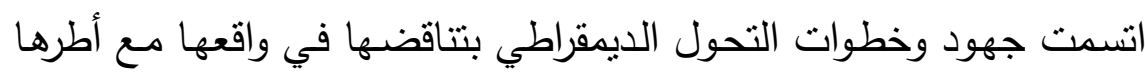

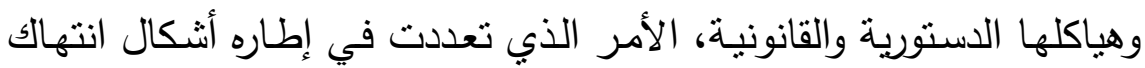


الأسس والمبادئ الدستورية والقانونية. وفي هذا السباق اتسعت الفجوة بين

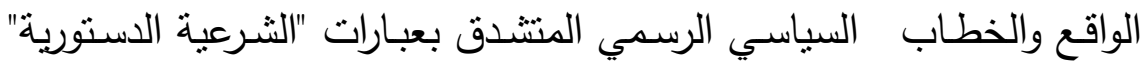

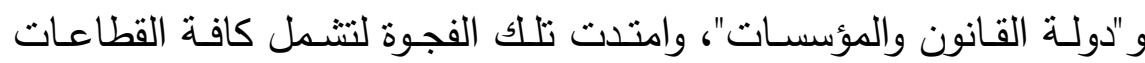

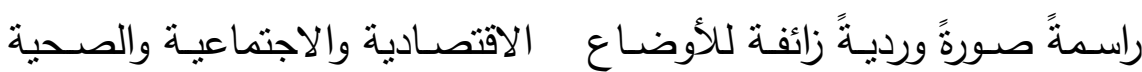
والتعليمية والوظيفية وغيرها، متتاقضةً تناماً مع الواقع الذي تعيشـه الأغلبية الساحقة)(rv)

وقد مثلت الأوضاع الاقتصسادية عاملاً محورياً حاسماً في فنثل جهود

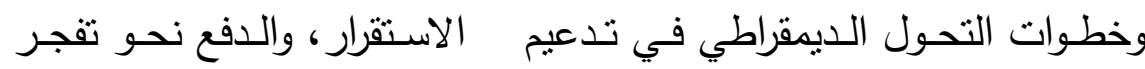
الأوضاع في المنطقة العربية، فقد ترافقت تلك الجهود والخطوات مـع تدهور الظروف الاقتصادية في الغالب لقطاعات واسعة من الشعوب، ولم تقلح التصريحات الحالمة للمسؤولين الرسميين عن المردودات الايجابية لسياسات

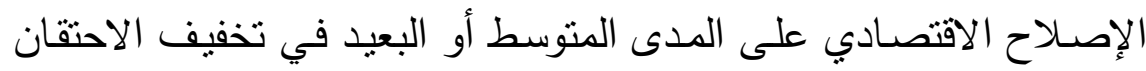
المتتامي لدى قطاعات مجتمعية كبيرة سئمت انتظار تلك المردودات على الإدي

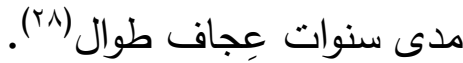

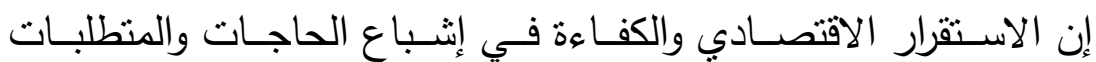

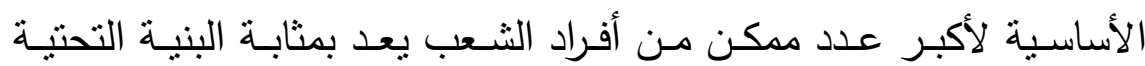

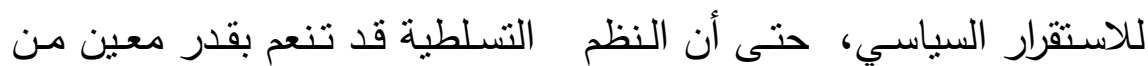
الاسـتقرار في حالـة نجاحها في تحقيـق درجـات معقولـة مـن الانجـاز الاقتصادي، إلا أن تحقق الاستقرار أو استمراره في ظل نرافق الاستبداد والتسلطية مس تدهور الأوضـاع الاقتصسادية والمعيشية يعد أمـراً مستحيلاً.

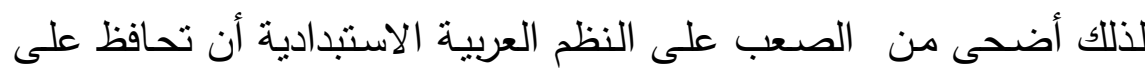

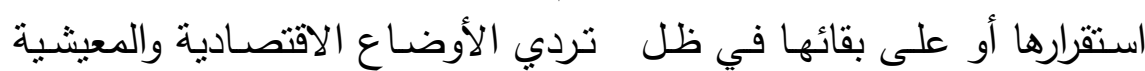
لقطاعات عريضة من شعوبها ولاسيما الثبابية منها.

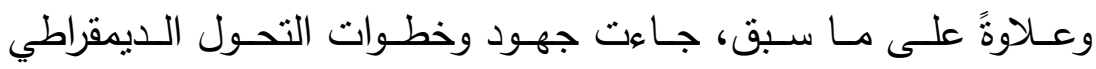
والإصـلاح السياسـي في العـالم العربـي فـي سـياق ثقافـة سياسـية غيـر 
ملائمسة، اتسـمت بالسـلبية والانقيـاد والعـزوف عـن المثــاركة الإيجابيـة،

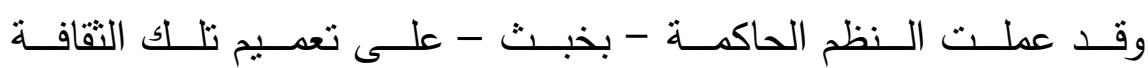
بتسطيح الوعي الجمـاعي وتسفيهه عبر الدعايات الإعلاميـة السـلبية

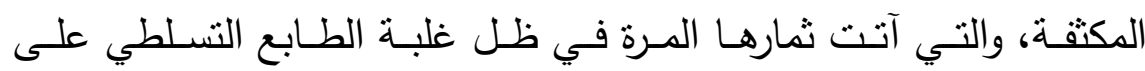

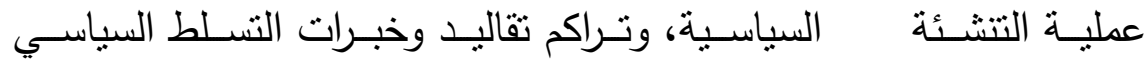

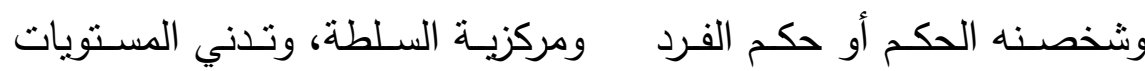

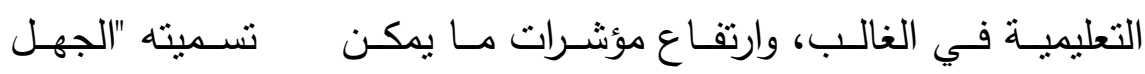

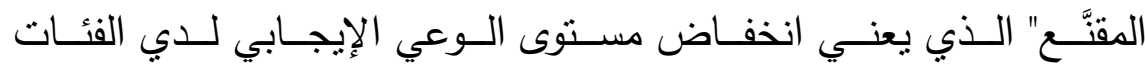

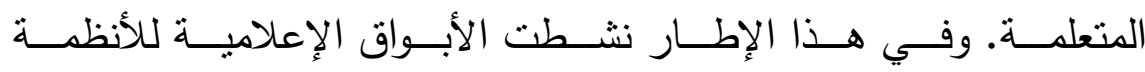

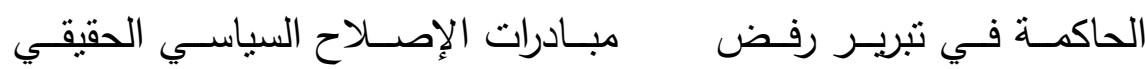

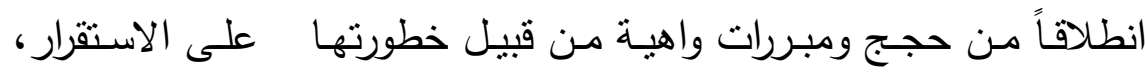

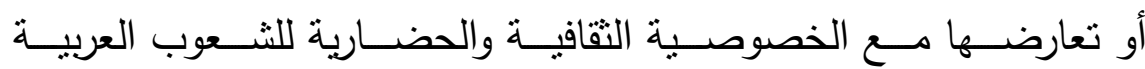

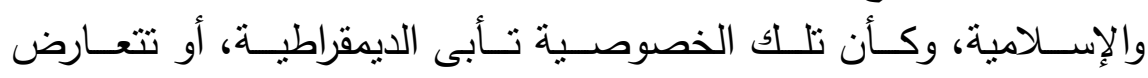

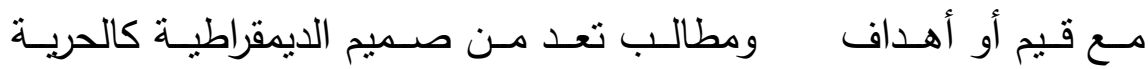

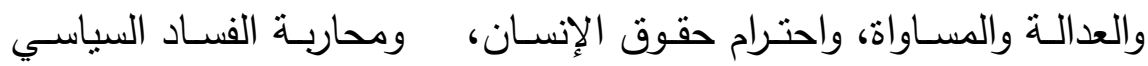
والإداري، وضـمان التتافسـية السياسـية و نزاهـة الانتخابـات، والالتـزام بأسس المساءلة والمحاسبة في العمل العام أو الحكومي.

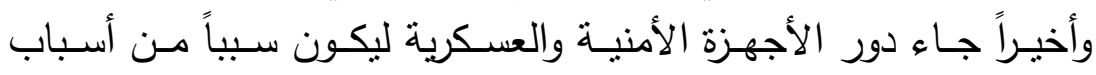

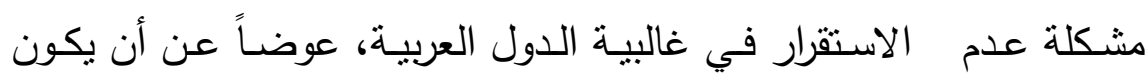

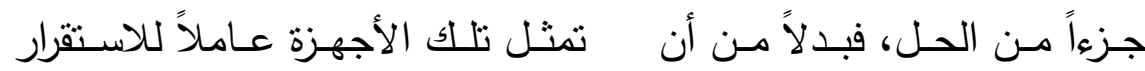

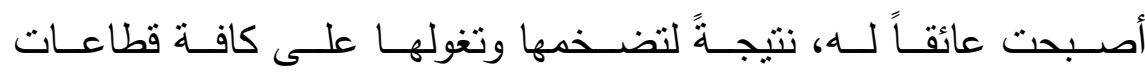

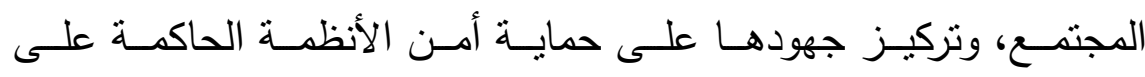

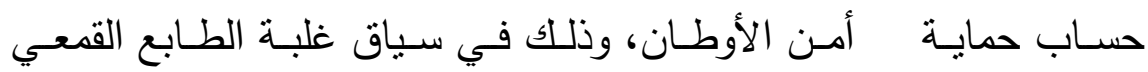

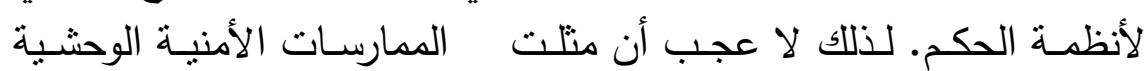


القتــة التـي قصـمت ظهر أنظمـة الحكم الاسـتبدادية، و الثــرارة التي

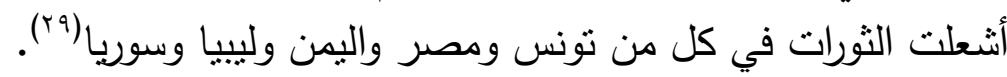

رابعا: المسارات المضطرية للثورات في المنطقة العربية بعد 11 +.

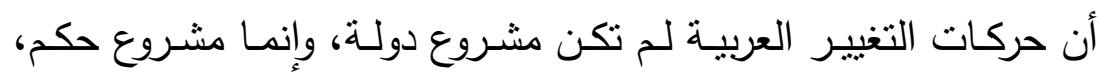

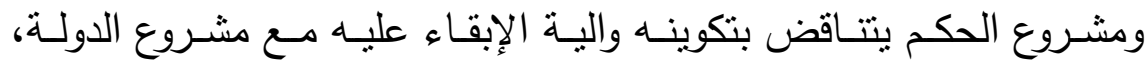

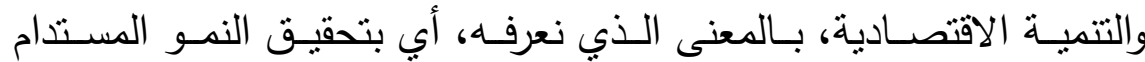

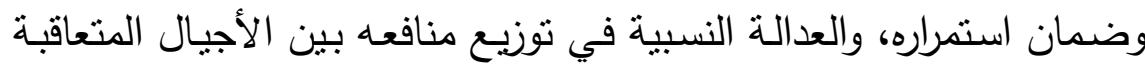

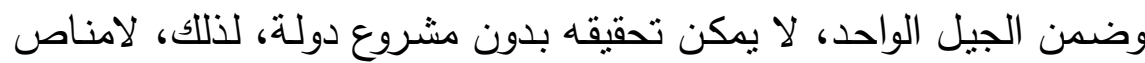

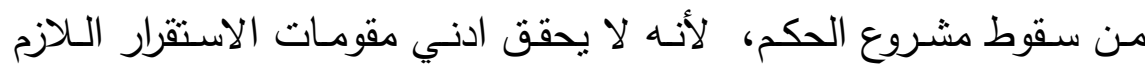

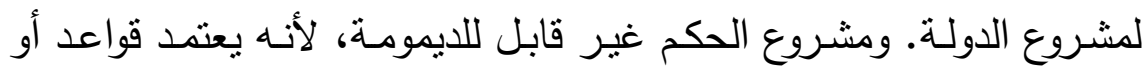
أسس هشة تزداد خطرا وهثاشا بمرور الزمن (·r).

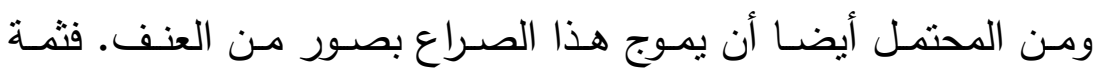
عوامل تتتج هذا العنف في مجتمع ما بعد الثورة، أهمها:

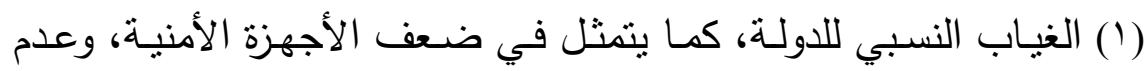

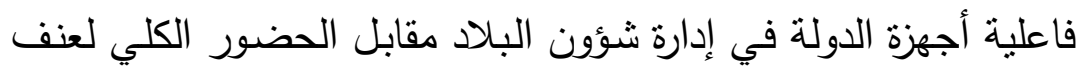

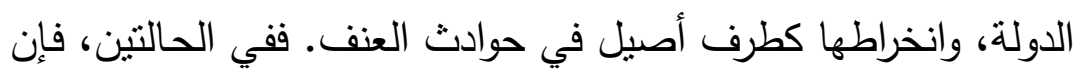
الدولة سوف تسهم في إنتاج العنف. غياب الرادع الثقافي والقانوني، وحضور الغريزة بقوة في السلوك.

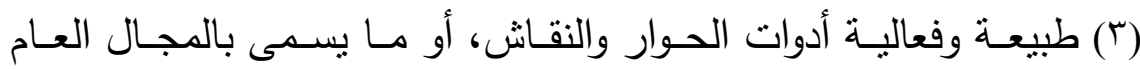
والذي يعبر - إذا كان فعالا- عن القدرة علي التدبر التير (Public Sphere) العقلي والتفاوض. وعندما يضعف هذا المجال أو يصيبه الوهن، فئن فئن النقاش يفقد قدرته علي التدبر والتفاوض، ويصير صياحا أو إملاء('آ). مما لاشـك فيه أن أي ثورة تمر بمرحلتين، تتعلق أولاهمـا بهدم النظـام

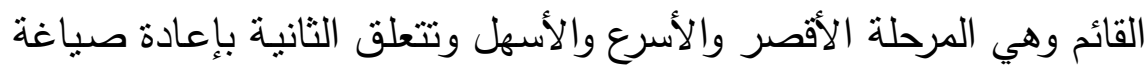


النظام السياسي وهي المرحلة الأصعب والأطول، ومن اللافت للنظر ان

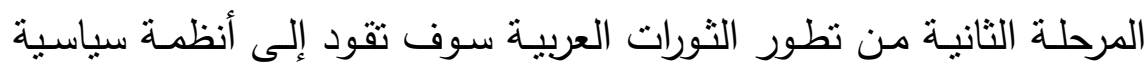

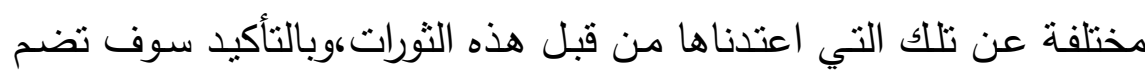

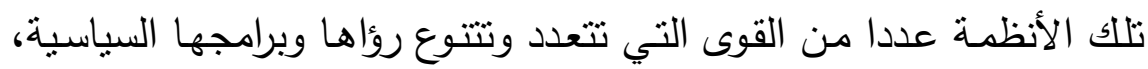

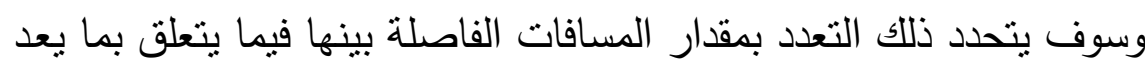

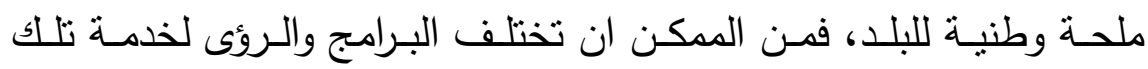

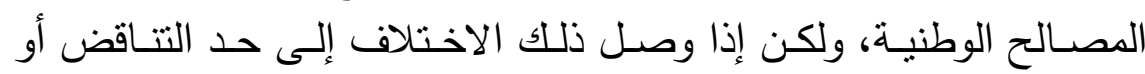

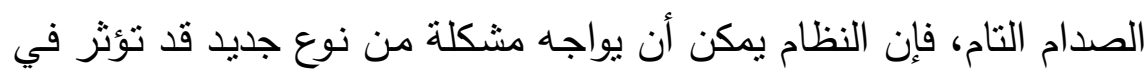

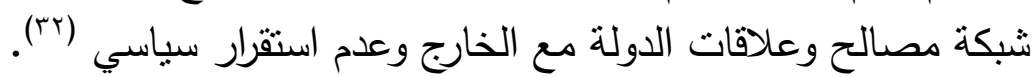

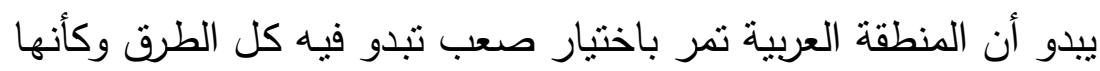

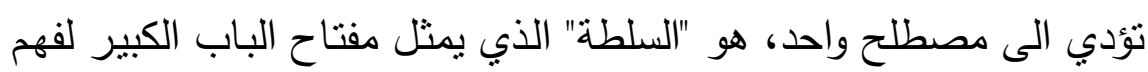

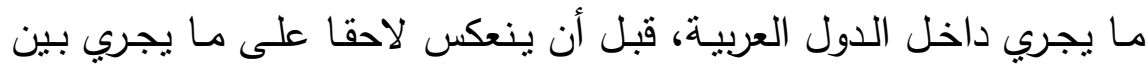

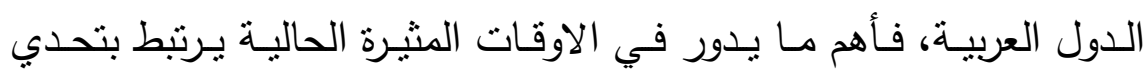

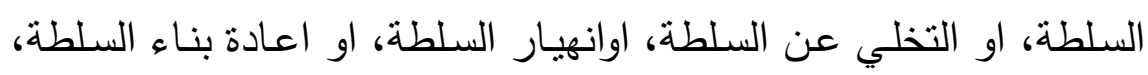

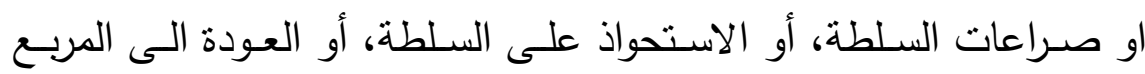

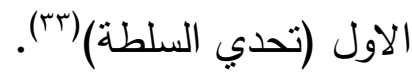

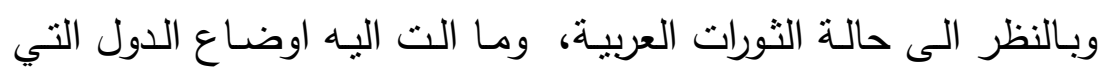

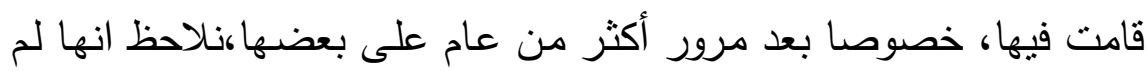

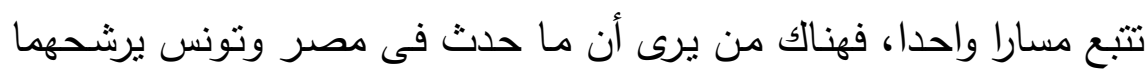

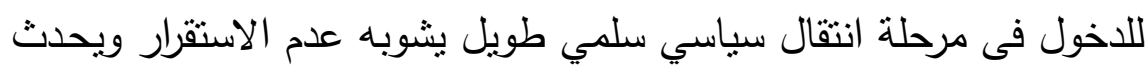

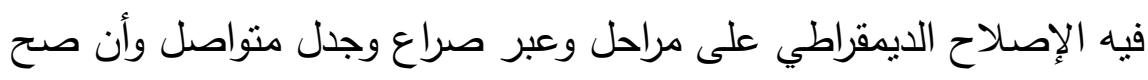

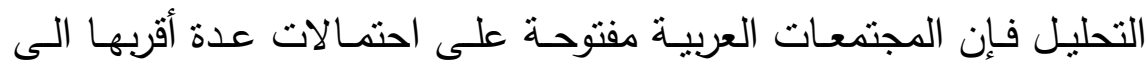

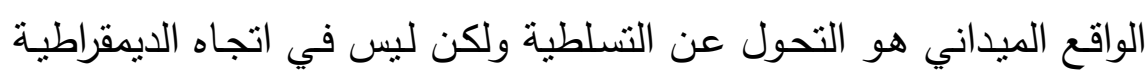

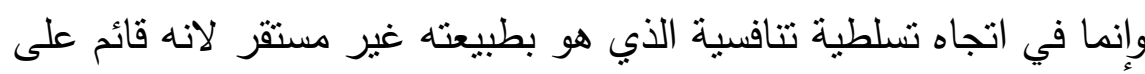

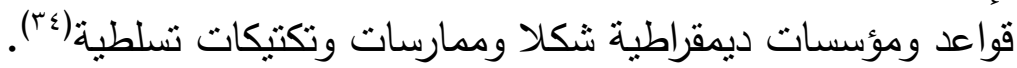


ففي مصر تم تغبير النظام دون تغيير فلسفة النظام وبنيته الى حد انلك

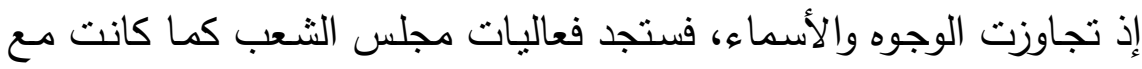
النظام السابق وان اختلفت الموضوعات، او محتوى القرارات التي هي من ون

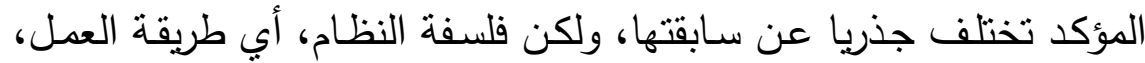

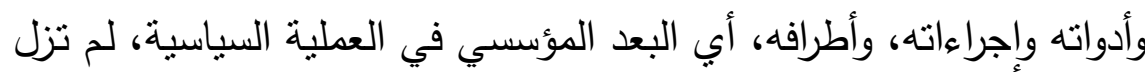

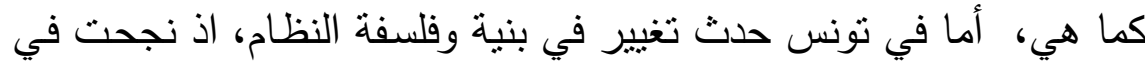
أحداث تغيير جذري في بنية النظام وأدواته وطريقة عمله، أما الحالة اليمنية

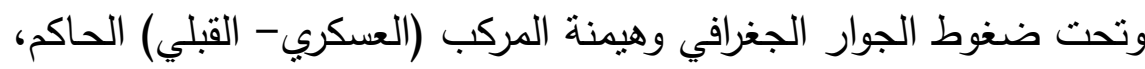

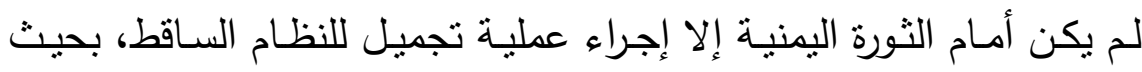
تعطي انطباعـا بتغيير النظام، ثم جـاءت السلوكيات التاليـة للنظام الجديد لتعييد تكرار نفس منهجيـة النظام القديم في نشـاطات الجماعات المسلحة المناوئة (ro) - (ro)

وتقدم الحالتان الليبية والسورية نموذجاً مختلفاً تعكسه دلالة العلم الثوري، ففي كلا الحالتين، رفعت جماهير الثورة علما يعود لنظام سابق عن النظام الذي قامت الثورة لإسقاطه، ففي الحالة اللبيية كان علم الملكية، وفي الحالة السورية كان علم الانتداب البريطاني،(זَ). وفي كلتا الحالتين بعكس العلم

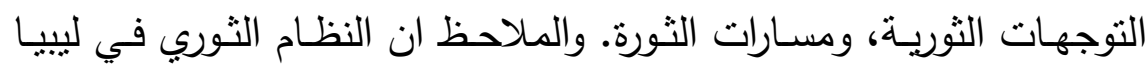

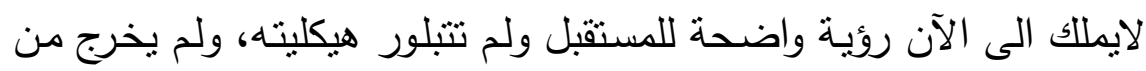
تبعات إسقاط النظام بعد، ويعاني أزمة بناء دولة، لان القوى التي شاركت وإن

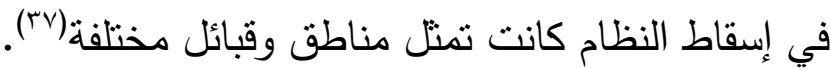
وكان التحدي الرئيسي في دول الثورات العربيـة هو كيفيـة إدارة عمليـة التحول من النظم التي أسقطتها الثورة إلى أوضـاع جديدة تلبي طموحات

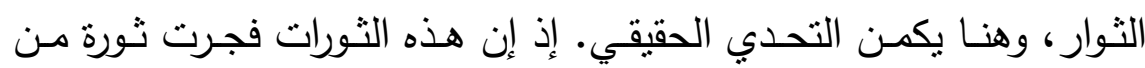

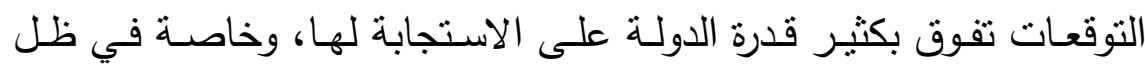
تتاقص الموارد بشكل غير مسبوق. ففي مصر وتونس، كانت السياحة مثنلا 
تسهم بما يتراوح من ( 1 ـ r I ) \% من الناتج القومي عند اندلاع الثورة، وقد

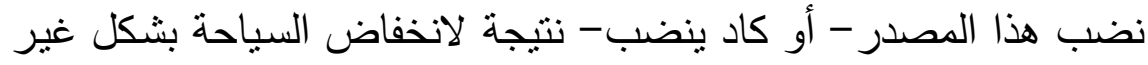

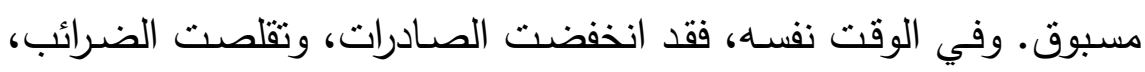

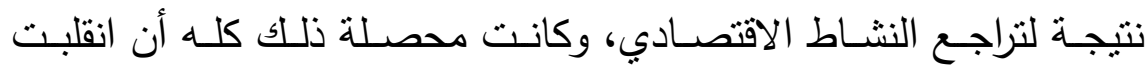

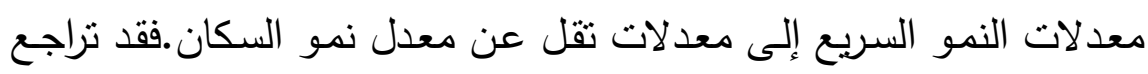

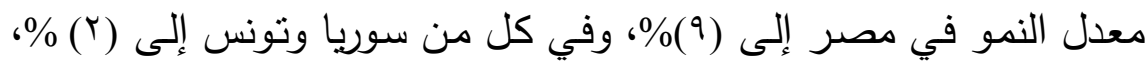

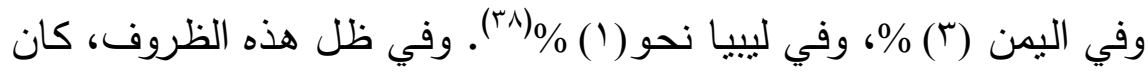

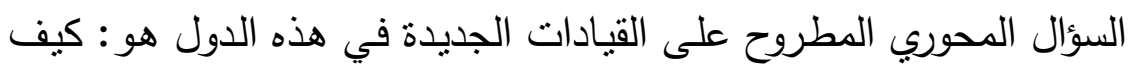

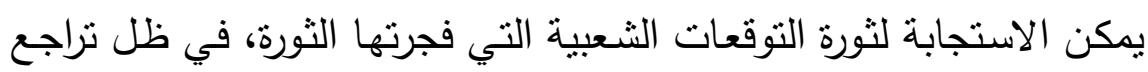
النمو ونقص الموارد؟ لا يجدي هنا وصف هذه التوقعات بالمشروعة وغير

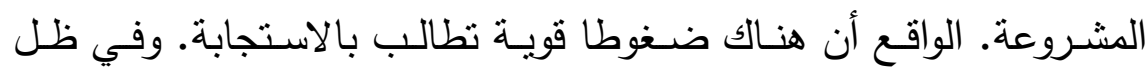

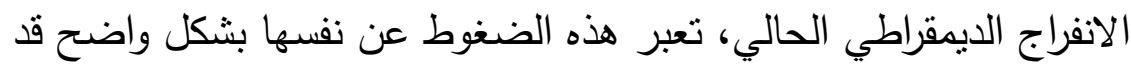

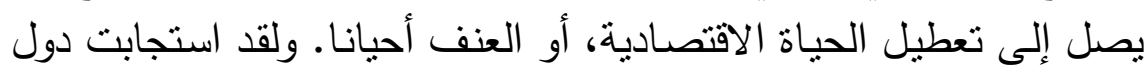

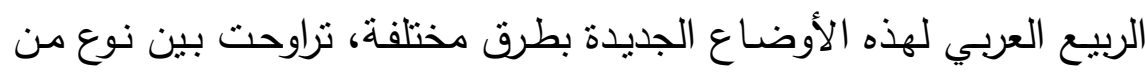

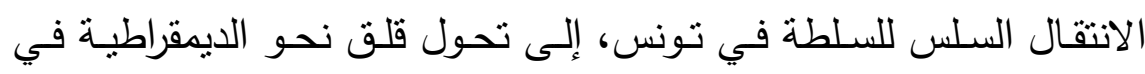

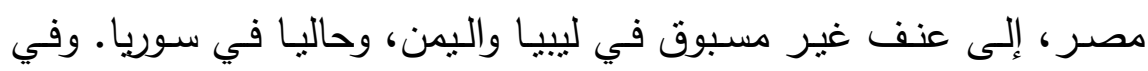
الواقع، لا تزال التطورات غير مستقرة في هذه الدول باستثناء تونس ومصر ،

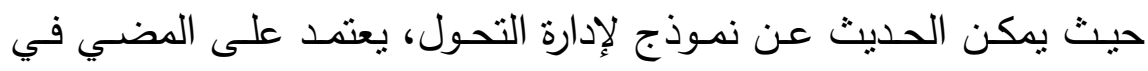

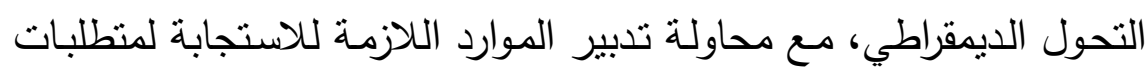
استعادة النشاط الاقتصادي. من جهة أخرى استطاعت القوى الإسـلامية في ثـلاثث من دول الربيع

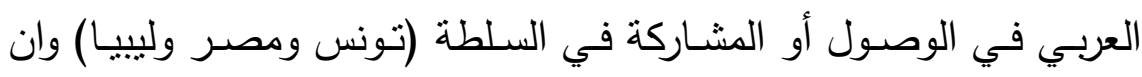

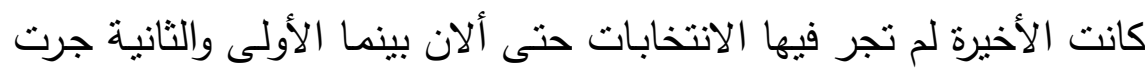

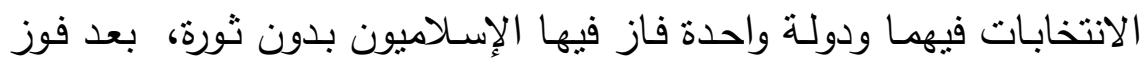
حزب العدالة والتتمية في المغرب، في ظل انتخابات جرت في ظل ثوابت 
ومرجعيات التطام السياسي الملكي، وبالرغم من بين هذه القوى سالفة الذكر

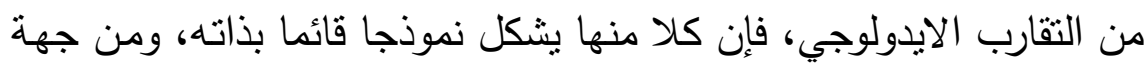
أخرى لم يمثل وصول الإسلاميين للحكم في بعض البلدان العربية نوعا من بن بن

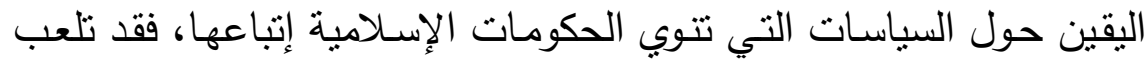

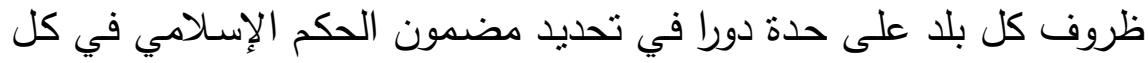
منها. وقد يقبل البعض أن يبقى مجرد شريك في الحكم لاحاكما فعليا، كما دوري

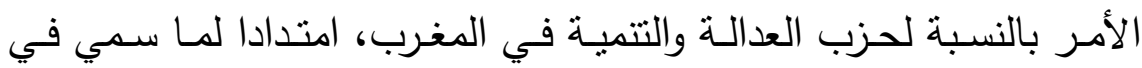
أواخر التسعينات بسياسة التتاوب التي ابتدعها الملك الراحل الحسن الثاني آنذاك لاحتواء المعارضـة اليسـارية، وقد تشـهـ بعضـها صـراعات مريرة بين

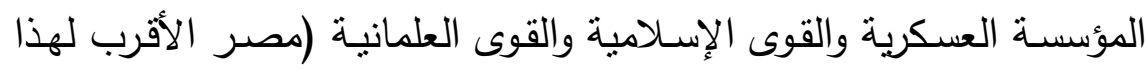

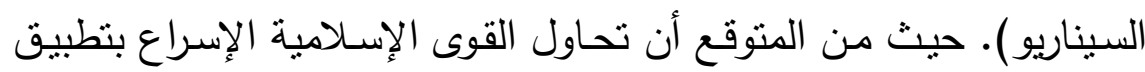

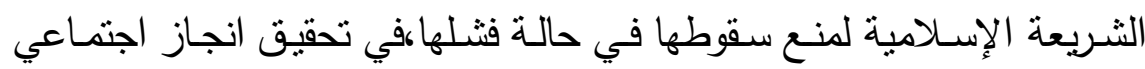
اقتصادي سريع (rq") كمـا قد يسفر حكم البعض،منثل حزب النهضـة في تونس، عن نجاح نسبي ليدعم صورة الحكم الإسلامي على الطريقة "الاردوغانية".

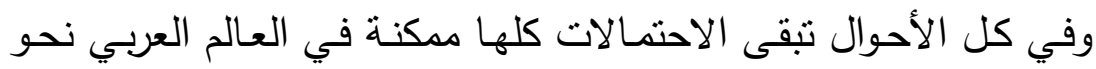

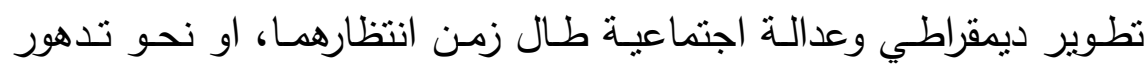
واضطرابات واسعة تقضي على القليل الذي تم انجازه على طريق الحداثة في الماضي. أما بقية الدول التي تعرف حراكًا يطالب بالإصـلاح لا بالتغيير، وتتمثنل هذه في كل من الأردن والمغرب، ويبدو أن المغرب تمكن من ترويج فكرة

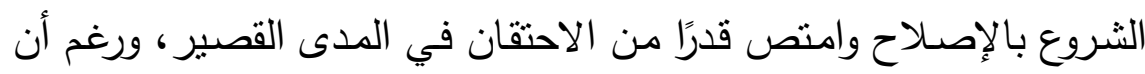
الملك استشعر موجة الثورات العربية فقام بالدعوة لعقد الانتخابات البرلمانية قبل موعدها بعام إلا أن سيطرة حزب العدالة والتتمية على السلطة التشربعية

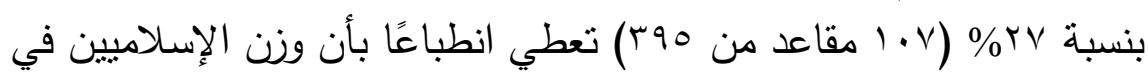


المغرب يجعل الملك أكثر اطمئنانًا من غيره من الحكام العرب للعام القادم

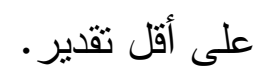

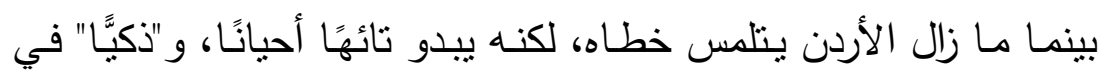

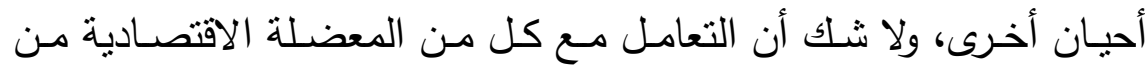
ناحية والتوتز الاجتماعي من ناحية أخرى يمثل مؤشرًا على ما ذكرنا.

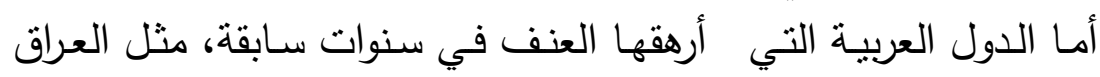
والجزائر والسودان، وبيدو أن الجزائر هي الأقرب منها للسبطرة على أزمتها

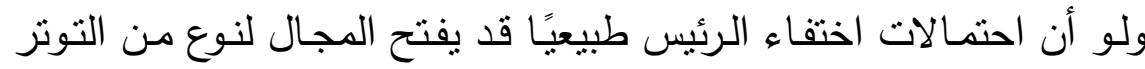

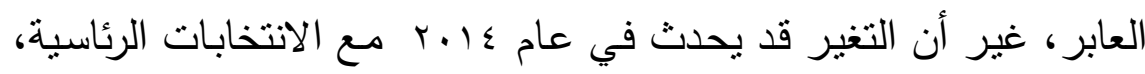

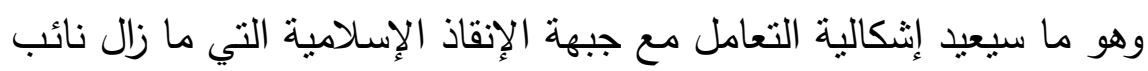

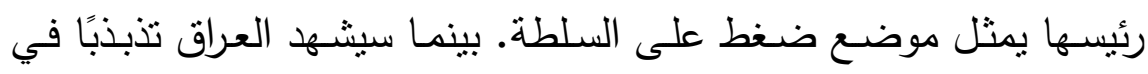

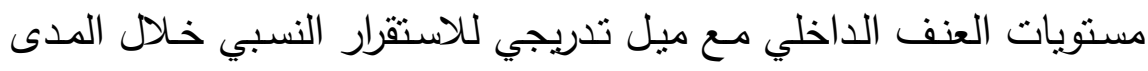

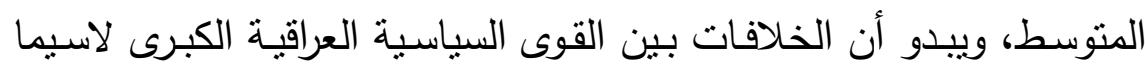
بعد انسـاب القوات الأميركيـة تشير إلى مستوبين مـن الخلافـات، الأول:

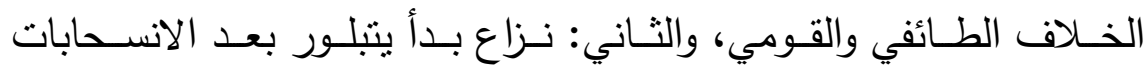
والانثقاقات من داخل كل كتلة من الكتل السياسية.

خاتمة

أن الاهتمـام بتطبيـق الديمقراطيـة فـي الـنظم المسـتبدة مســألة مهمــة

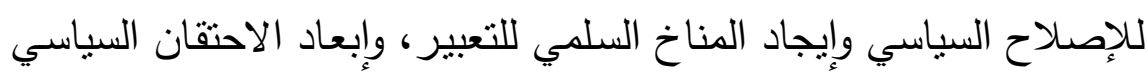

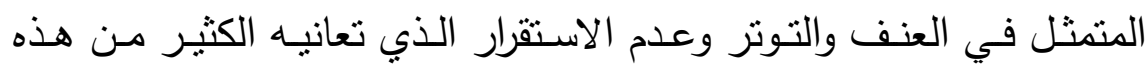

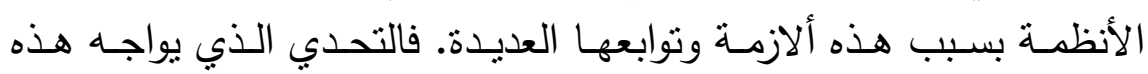

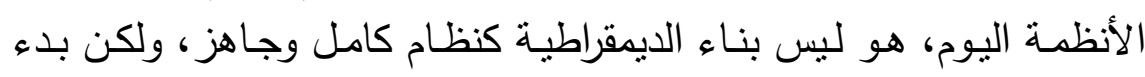

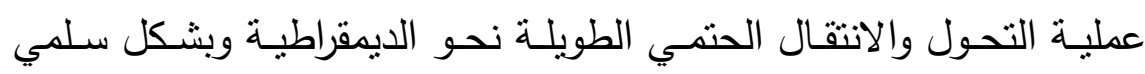

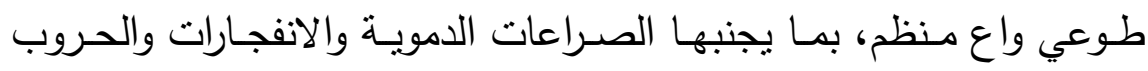




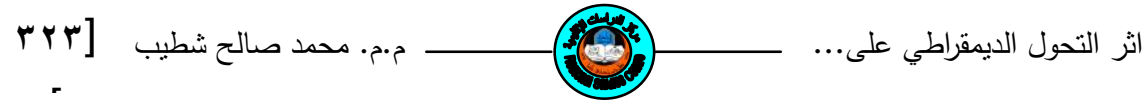

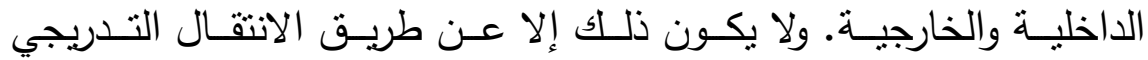

$$
\begin{aligned}
& \text { والسلمي، شريطة توافر أسس ومتطلبات ذلك، حتى يحدث الانتقال أثرا }
\end{aligned}
$$

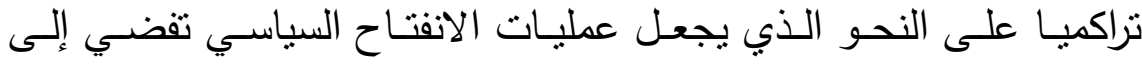

$$
\begin{aligned}
& \text { تحولات كمية وكيفية حقيقية على صعيد عملية الدمقرطة، وذلك لان التحات التحول }
\end{aligned}
$$

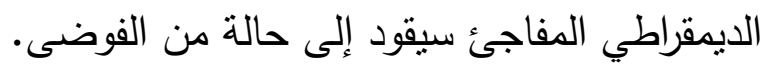

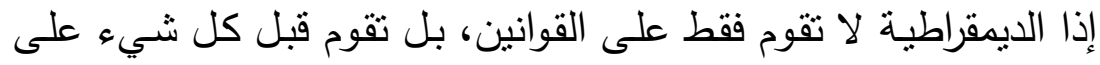

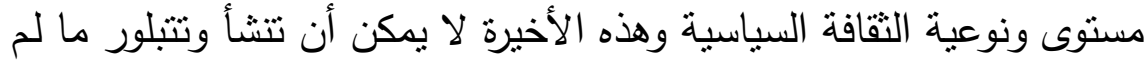

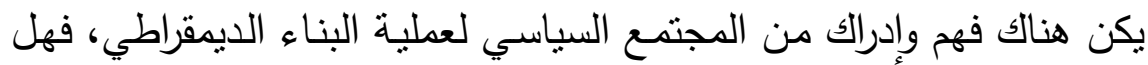

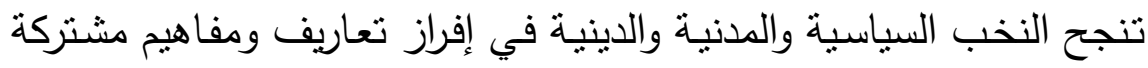

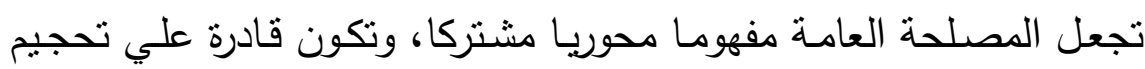

$$
\begin{aligned}
& \text { وضبط الطاقة المسكونة بالعنف والقادمة من أسفل، أم أن هذه الطاقة كبيرة }
\end{aligned}
$$

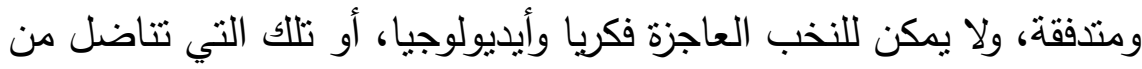

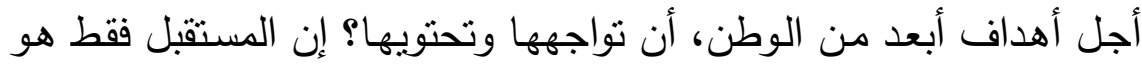

$$
\begin{aligned}
& \text { القادر على أن يجيب عن هذا السؤال. }
\end{aligned}
$$

\title{
The impact of democratization on political stability in the Arab States
}

\section{Mohammed Saleh SHtaib}

Assistant Lecturer / Faculty of Political Science / University of Mosul

\begin{abstract}
It is certain certainly democracy is not only institutions and procedures, but also it based on a political culture that includes a system of values and ideas that dedicate the practice of democracy, we can say that the Arab revolutions was a surprise and that the majority
\end{abstract}


of Arab countries are not ready for entitlement to political of this size, which created systems political pluralism without getting into internal conflicts and political tension .So, the challenge that facing these systems today, is not builti by democracy as complete and ready system, but the be yinnig of the conversion process and transition inevitably lead to democracy, peaceful, chosen and consciously structured that will make it avoid avert bloody conflicts and explosions and internal and external wars.

المصادر

(1) إكرام عبدالقادر بدر الدين، " اتجاهات التحول الديمقراطي في شرق آسيا "، في محمد السيد

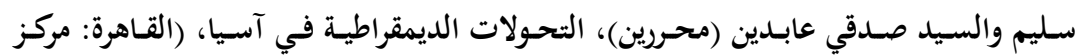

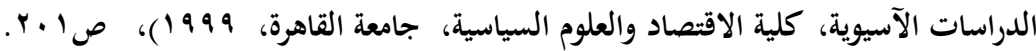

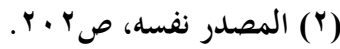

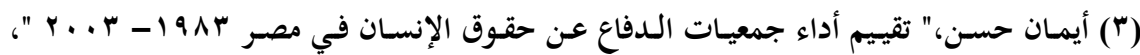

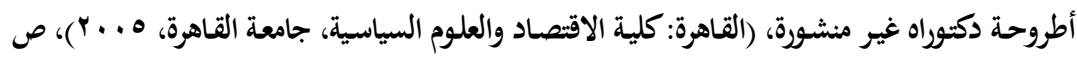

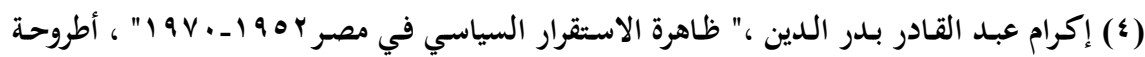

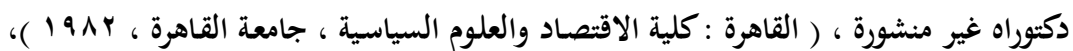

(•) عبد الكريم عبد لاني،" المعارضة السياسية والتحول الديمقراطي بالمغرب"، أطروحة دكتوراة غير

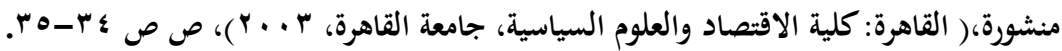

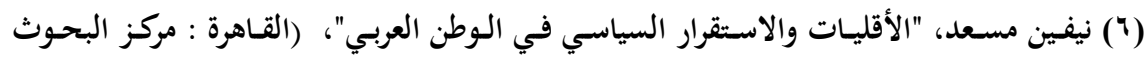

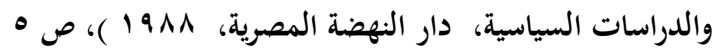

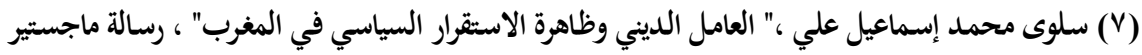

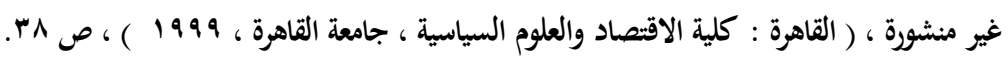

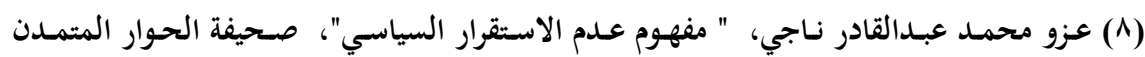

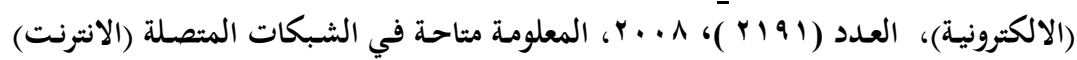

http:ww //www.ahewar.org : : 
(• (1) محروس أحمد حسن ،" المؤسسة العسكرية وظاهرة عدم الاستقرار السياسي في السودان في

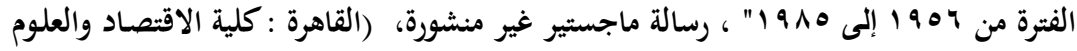

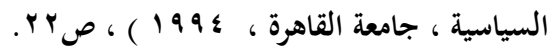

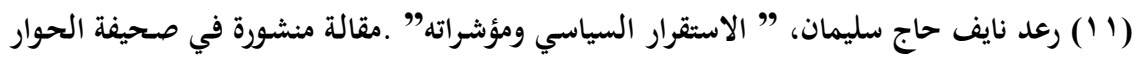

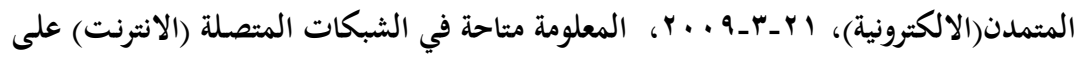

\section{http://www.ahewar.org}

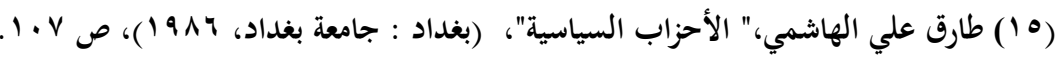
(7 (1) وصـال العزاوي، الثورات العربية واستحقاقات التغيير، مجلة شؤون الأوسط، (القاهرة، مركز

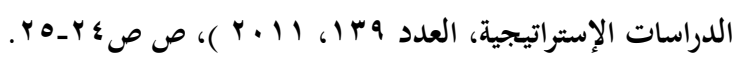

( $1 \vee$ )Theda Skeeple, States and Social Revolutions ;Acomparative Analysis. Of

France, Russia. And CHINA, Cmobridge University Press,1979, p.p 33-34

$$
\begin{aligned}
& \text { (1^ (1) محسن عوض، الانتقال إلى الديمقراطية في الوطن العربي، مجلة المستقبل العربي،( بيروت: }
\end{aligned}
$$

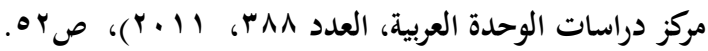

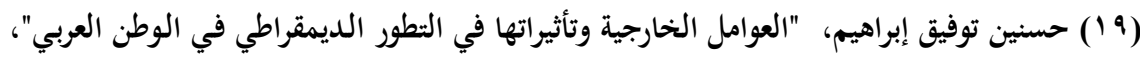

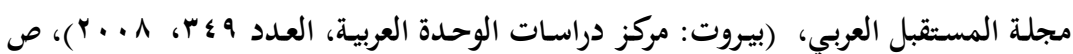

$$
\begin{aligned}
& \text { ص. }
\end{aligned}
$$

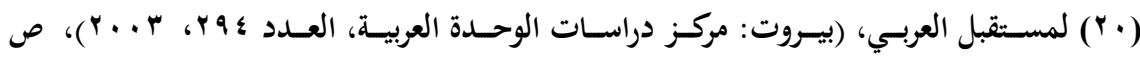

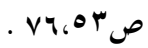

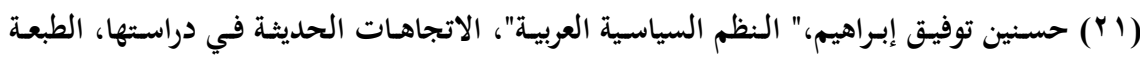

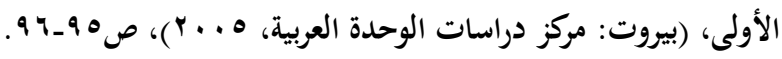

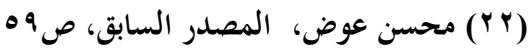

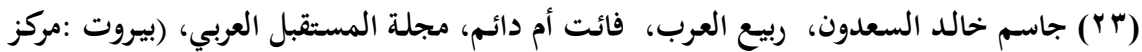

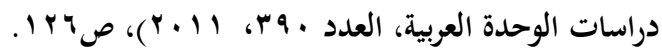

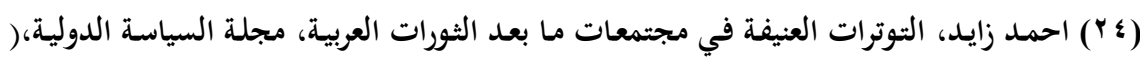

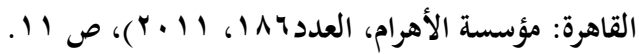




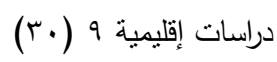

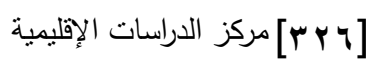

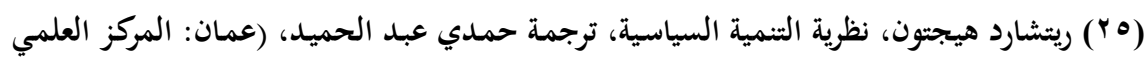

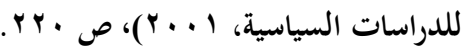

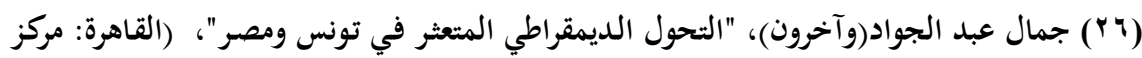

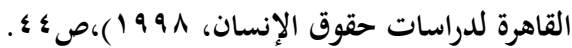

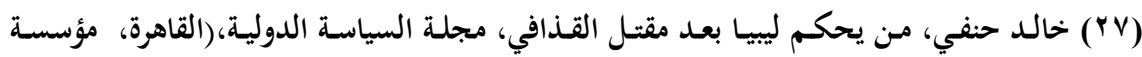

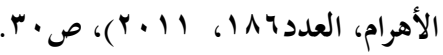

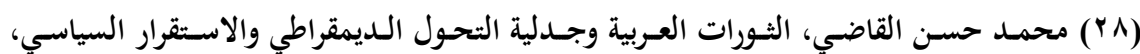
المعلومة متاحة في الشبكات المتصلة الانترنت الثرات على الرابط:

http://www.elsyasi.com

$$
\begin{aligned}
& \text { (9 Y) مصطفى كامل السيد ( محررا )، الإصلاح السياسي في الوطن العربي، ( القاهرة: مركز دراسات }
\end{aligned}
$$

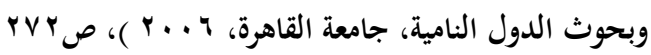

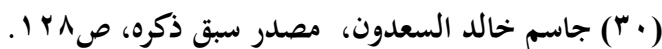

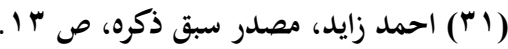

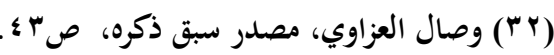

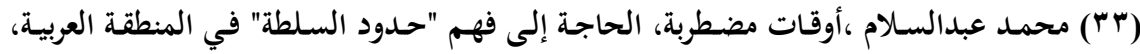

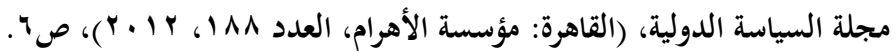

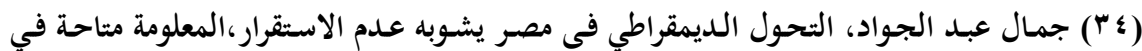

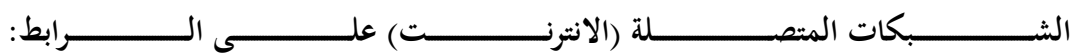

http://www.youm7.com/News

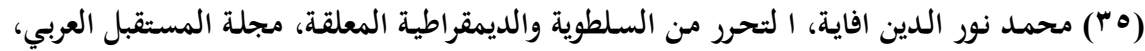

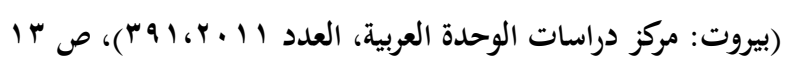

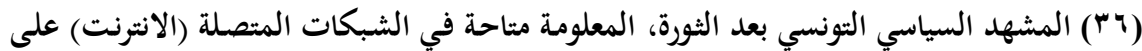
الرابط:

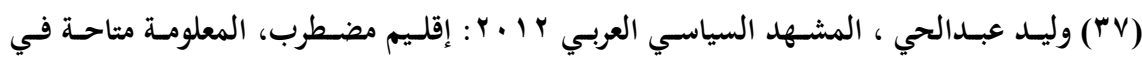

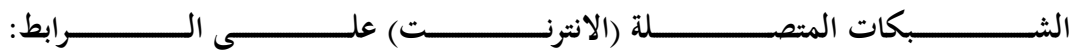

http://studies.aljazeera.net

(†^) سمير رضوان، ثورة في التوقعات ونقص حاد في الموارد بعد الثورات العبية، مجلة السياسة

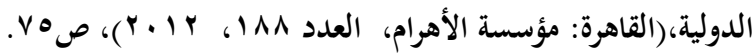




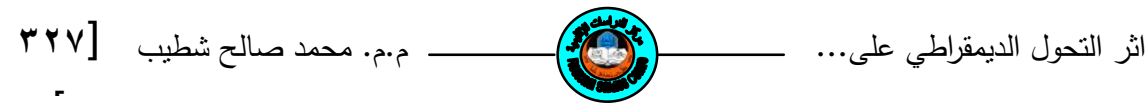

(") ولاء البحيري، الجغرافية المحيرة: كيف تفكر الثيارات الإسلامية في معضلة الإطار الإقليمي،

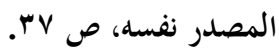

